San Jose State University

SJSU ScholarWorks

Master's Theses

Master's Theses and Graduate Research

1992

\title{
The Effect of age, gender, and ethnic origin on flexibility as measured by the sit and reach test and the Leighton flexometer
}

Susan De La Torre

San Jose State University

Follow this and additional works at: https://scholarworks.sjsu.edu/etd_theses

\section{Recommended Citation}

De La Torre, Susan, "The Effect of age, gender, and ethnic origin on flexibility as measured by the sit and reach test and the Leighton flexometer" (1992). Master's Theses. 451.

DOI: https://doi.org/10.31979/etd.rcgx-ar7u

https://scholarworks.sjsu.edu/etd_theses/451

This Thesis is brought to you for free and open access by the Master's Theses and Graduate Research at SJSU ScholarWorks. It has been accepted for inclusion in Master's Theses by an authorized administrator of SJSU ScholarWorks. For more information, please contact scholarworks@sjsu.edu. 


\section{INFORMATION TO USERS}

This manuscript has been reproduced from the microfilm master. UMI films the text directly from the original or copy submitted. Thus, some thesis and dissertation copies are in typewriter face, while others may be from any type of computer printer.

The quality of this reproduction is dependent upon the quality of the copy submitted. Broken or indistinct print, colored or poor quality illustrations and photographs, print bleedthrough, substandard margins, and improper alignment can adversely affect reproduction.

In the unlikely event that the author did not send UMI a complete manuscript and there are missing pages, these will be noted. Also, if unauthorized copyright material had to be removed, a note will indicate the deletion.

Oversize materials (e.g., maps, drawings, charts) are reproduced by sectioning the original, beginning at the upper left-hand corner and continuing from left to right in equal sections with small overlaps. Each original is also photographed in one exposure and is included in reduced form at the back of the book.

Photographs included in the original manuscript have been reproduced xerographically in this copy. Higher quality $6 "$ x 9 " black and white photographic prints are available for any photographs or illustrations appearing in this copy for an additional charge. Contact UMI directly to order.

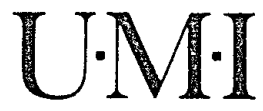

University Microlıms Internatıonal

A Bell \& Howell Information Company 

The effect of age, gender, and ethnic origin on flexibility as measured by the Sit and Reach Test and the Leighton Flexometer

De La Torre, Susan Theresa, M.A.

San Jose State University, 1993 



\title{
THE EFFECT OF AGE, GENDER, AND ETHNIC ORIGIN ON FLEXIBILITY AS MEASURED BY THE SIT AND REACH TEST AND THE LEIGHTON FLEXOMETER
}

\author{
A Thesis \\ Presented to \\ The Faculty of the Department of Human Performance \\ San Jose State University
}

In Partial Fulfillment of the Requirements for the Degree

Master of Arts

By

Susan De La Torre

December 1992 

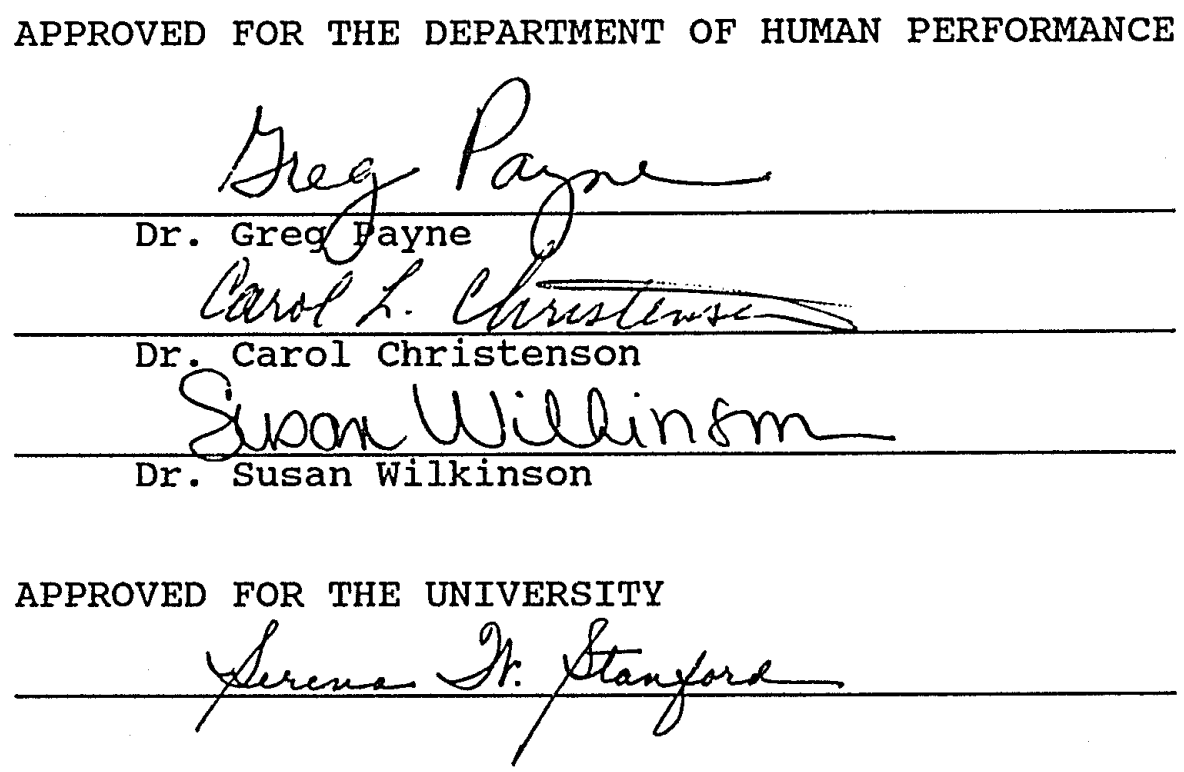


\section{ABSTRACT}

THE EFFECT OF AGE, GENDER, AND ETHNIC ORIGIN ON FLEXIBILITY AS MEASURED BY THE SIT AND REACH TEST AND THE LEIGHTON FLEXOMETER

$$
\text { by Susan De La Torre }
$$

The effect of age, gender, and ethnic origin on flexibility as measured by the Sit and Reach Test (SRT) and the Leighton Flexometer were examined. Flexibility measures were taken for 265 subjects, 115 males and 150 females. Three ethnic origins (Asians $\mathrm{n}=90$, Caucasian $\mathrm{n}=84$, and Hispanics $n=91$ ) were selected from the six, ten, and fourteen year-old age groups to measure for flexibility. Significant differences were noted among age groups for flexibility, particulary between the six and fourteen yearolds for both the SRT and the Leighton Flexometer. Females scored significantly higher in flexibility than the males on both instruments. No significant differences were noted between ethnic origins. Finally, measures from the Leighton Flexometer and the SRT were found to be moderately correlated $(r=.68)$ for the determination of flexibility

In conclusion, this study reinforces previous research that females outperform males in overall flexibility. Additional research is needed on age comparisons to determine factors that influence flexibility. Flexibility differences as related to ethnic origin also need to be reexamined. 


\section{Acknowledgements}

I would like to thank my advisor, Dr. Greg Payne for his tremendous patience and guidance throughout the entire research.

I am grateful to the members of my committee, Dr. Susan Wilkinson and Dr. Carol Christenson for their time and involvement in this study and their helpful suggestions.

I wish to extend my gratitude to the Physical Education teachers and classroom teachers of Evergreen School District and Sunnyvale School District for allowing me to conduct my research at their schools.

A special thanks and deepest appreciation to my motherin-law, my friend, for her encouragement in finalizing this project.

Finally, I would like to express my deepest thanks to my husband, steve, for all the support, love, and patience in completing this thesis. 
Chapter 1

Introduction. . . . . . . . . . . . . . . . . 1

Statement of the Problem. . . . . . . . . . . 8

Statement of the Purpose. . . . . . . . . . . 8 Hypotheses. . . . . . . . . . . . . . . 8 Delimitations . . . . . . . . . . . . . . 9 Limitations . . . . . . . . . . . . . . . 9 Definitions . . . . . . . . . . . . . . 10

Chapter 2

Review of Literature Introduction . . . . . . . . . . . . . . 12 Anatomy of the Lumbar spine . . . . . . . . . . 12

a) Muscular Control of Lumbar Region. . . . . . 13

b) Range of Motion of Lumbar Spine . . . . . . . 14 Research and Instrumentation of Flexibility . . . . . 18

a) Sit and Reach Test . . . . . . . . . . . 24

b) Leighton Flexometer. . . . . . . . . . . . 29 Gender, Age, and Flexibility. . . . . . . . . . 31 Motor Performance and Ethnic Origins. . . . . . . . 39 Summary . . . . . . . . . . . . . . . . 43 
Chapter 3

Methods

a) Introduction . . . . . . . . . . . 48

b) Subjects . . . . . . . . . . . . . 48 Measurement Procedures

a) Apparatus. . . . . . . . . . . . 49

b) Procedure. . . . . . . . . . . . . 50 Statistical Analysis . . . . . . . . . . . 53

Chapter 4

Results \& Discussion. . . . . . . . . . . . . 54

Chapter 5

Summary • • • • • • • • • • • • • • • • . 65

Conclusions . . . . . . . . . . . . . . 66

Recommendations .. . . . . . . . . . . 67

References. . . . . . . . . . . . . 69

Appendices

a) Consent Letter/Survey Form. . . . . . . . . 77

b) Letter of Permission from Evergreen School District 80

c) Letter of Permission from Middle Schools. . . . . 82

d) Letter of Permission from Publisher . . . . . . 84 


\section{List of Figures}

Figure

1. Lateral view of Vertebral Column . . . . . . . 16

2. Muscles Involved in Flexion and Extension. . . . . 17

3. Means and Standard Deviations for each Age Group for the Leighton Flexometer and the Sit and Reach Test . . . 57

4. Scattergram of Flexibility as Measured by the Leighton Flexometer and the SRT . . . . . . . . . . 61

\section{List of Tables}

Table

1. Means and Standard Deviations by Age as Measured by the Leighton Flexometer and the SRT . . . . . . 55

2. Means and Standard Deviations by Gender as Measured by the Leighton Flexometer and the SRT . . . . . 55

3. Means and Standard Deviations by Ethnic Origin as Measured by the Leighton Flexometer and the SRT. . . 56

4. ANOVA Table for the 3-Factor Analysis of Variance of Leighton Flexometer Data . . . . . . . . . 59

5. ANOVA Table for the 3-Factor Analysis of Variance of SRT Data. . . . . . . . . . . . . . 59 
6. Post-Hoc Scheffe' Analysis of Significant Main Effects for Age as Measured by the SRT. . . . . . . . 60

7. Pearson Product Moment Correlation Coefficient Between the Leighton Flexometer and SRT Measures . . . . . 60 
Chapter 1

\section{Introduction}

The Sit and Reach Test (SRT) was developed by Wells and Dillion (1952) to measure low back flexibility. This test is included in most health-related physical fitness test batteries because maintaining hamstring and low back flexibility is believed to help prevent low back pain syndrome (AAHPERD, 1984). Even though the SRT is performed nationally on children as an indicator of flexibility, the score does not distinguish between the contributions of the low back and hamstrings to total performance (Cornbleet \& Woolsey, 1991). There may also be the need to examine the relationships between pelvic tilt in long sitting (an indirect measure of hamstring length) and low back flexibility (LBF) in the SRT position.

In research examining these two areas, Cornbleet and Woolsey (1991), asked subjects to perform the SRT by reaching forward maximally with their knees fully extended and ankles in a neutral dorsiflexion. The scores for the SRT were obtained and the final pelvic tilt angle was measured using an inclinometer placed over the sacrum. Although the correlation between SRT scores and pelvic tilt was statistically significant $(r=.80, \underline{p}<.05), 17 \%$ of the subjects had erroneous scores due to excessive posterior pelvic tilt or anthropometric factors. Based on these 
results, the authors concluded that contributions of the hamstring muscles and of pelvic tilt need to be considered in any attempt to measure low back flexibility.

Jackson and Baker (1986) conducted a similar study examining the relationships between the SRT and criterion measures of hamstring and low back flexibility in females between the ages of 13 and 15. Hamstring flexibility was measured by administering a maximum passive straight leg raise from each limb of the subject while a Leighton Flexometer was attached to the leg. Low back flexibility was measured by the SRT. They reported a moderate correlation ( $I=.64$ ) between the SRT and hamstring flexibility, but a low correlation ( $I=.28$ ) with low back flexibility. They concluded that the SRT was not a valid field test of low back flexibility.

In an identical study administered on adults, Jackson and Langford (1989) replicated the findings of Jackson and Baker (1986). Extreme consistency resulted between flexibility for this female sample and the subjects from the previous report on teenage females. The SRT demonstrated excellent validity as a measure of hamstring flexibility (.86), but was not a valid measure of low back flexibility (-.11). The SRT possessed excellent criterion-related validity ( $I=.89$ ) as a field test of hamstring flexibility and was moderately related $(I=.59)$ to low back 
flexibility. The flexibility of the females was also found to be consistent with past findings (AAHPERD, 1984; Kippers \& Parker, 1987). With regard to low back flexibility, there were no significant differences between males and females, which also conformed to past research (Kippers \& Parker, 1987)

The validity of the SRT in assessment of mobility of the vertebral column has also been criticized because of the involvement of hip movement (Kippers \& Parker, 1987). Kipper and Parker's findings indicated that the standing toe touch test is highly related to trunk and hip flexion but not to vertebral flexion $(r=.10)$. These results have direct hamstring and pelvic involvement implications for the SRT because the standing toe touch test has a similar measurement protocol from the standing position.

The actual movements of the lumbar spine are flexion, extension, lateral bending, and rotation. Compared to the joints of the extremities, there is relatively little motion in the individual facets joints of the lumbar spine. Major motion, such as flexion, primarily involves hip movement (Hoppenfeld, 1976).

Because so many segments are involved in movements of the spine, an exact determination of spinal mobility is difficult. In many cases, a single measure of flexibility is used to assess flexibility characteristics. A number of 
methods have been devised and used. The clinical

measurements most frequently used include indirect estimates of spinal mobility from skin landmarks (measurement of the widening distance between two fixed points on the back during forward bending), and the toe touch test, which is the subjects fingertip distance from the floor while in forward flexibility. Published studies of lumbar spinal movement have included radiographic and photographic techniques, plus direct measurements using a wide variety of equipment and methods including specialized goniometers, inclinometers, flexible rulers, skin distraction methods, spondylometers and other clinical assessment devices (Burdett, 1986; Hart \& Rose, 1986; Troup, Hood, \& Chapman, $1976)$.

The Leighton Flexometer has also been recognized as a valid and reliable measure for measuring flexibility (Hupprich \& Sigerseth, 1950; Leighton, 1955). This instrument consists of a weighted $360^{\circ}$ dial and pointer that operates freely and independently. The subject's movement can be recorded through a variety of ranges of motion. In a study by Docherty and Bell (1985), the Leighton Flexometer was utilized to measure the relationship between selected anthropometric measures of linearity and measures of flexibility relative to age and gender. Five measures of limb and trunk length were taken in addition to three linear 
measures of flexiblity and six measures of angular displacement using the Leighton Flexometer. For trunk flexion and extension the females showed greater flexibility than the males. For the SRT, the females again showed higher levels of flexibility than males with a significant age by gender effect (Docherty \& Bell, 1985).

Some of the controversy regarding the relationship of flexibility to age and gender may be a function of the type of measures used. Research has found either an increase or a decrease in flexibility during the growing years (Buxton, 1957; Gallahue, 1982; Hupprich \& Sigerseth, 1950). In an Illinois fitness study that used AAHPERD Health-Related Fitness Test, 9 and 11 year-old males had more abdominal strength and the 11 and 12 year-old females, less flexibility (Bischoff \& Lewis, 1987).

Gender differences have also been reported for many motor tasks. Gender differences have been reported in large scale meta-analyses for motor activity level, motor performance, proportional reasoning, and spatial ability (Eaton \& Enns, 1986; Hyde, 1984; Nelson, Thomas, Nelson \& Abraham, 1986; Thomas \& French, 1985). In the two metaanalyses of motor performance and activity, the gender differences were related to age at least through adolescence. Thomas and French (1985) reported that gender differences were small or nonexistent in 19 of 20 motor 
tasks for children at three years of age. However, they found relatively large gender differences in throwing as early as age three. In addition, boys were observed to be more active than girls even in infancy (Eaton \& Enns, 1986). These findings suggest that heredity may be involved in the development of gender differences (Thomas \& French, 1985). A decline in the ranges of all lumbar movements with increasing age has also been noted. In old age, the ranges of lumbar movement in men and women become almost identical (Twomey, 1987). This evidence seems to indicate that one age is as good as another to study the structure of flexibility as long as the study is limited to a small age range (Harris, 1969).

Ethnic differences in relation to motor performance have been investigated in several studies (DiNucci \& Shows, 1977; Hutinger, 1959; Ponthieux \& Barker, 1965; Stone, 1966). Factors of body composition and physiological variables and the socioeconomic status of the children is also believed to be a variable that contributes to ethnic differences in motor performances (Lee, 1980; Scott, Ferguson, Jenkins, \& Cutter, 1955).

Hutinger (1959) investigated the differences in speed between Black and Caucasian children as measured by the 35yard dash, and found that Black children were superior in speed to Caucasian children. Examination of ethnic 
differences in physical fitness found Black males exceeded the Caucasian males significantly in five components of physical fitness and the Black females surpassed the Caucasian females on four measures of the AAHPER Youth Fitness Test (Ponthiuex \& Barker, 1965).

In a study that examined Black and Caucasian children from a low socioeconomic area, subjects were tested on a running and jumping task (standing broad jump and the 30yard dash). Also tested were the parents who were administered the orthner scale which measures the degree to which a parent attempts to restrict the autonomy and mold the attitudes of a child. Results indicated greater running and jumping skills for children reared by nonauthoritarian mothers. Black children, regardless of the parental style, showed greater skill than Caucasian children in both running and jumping (Lee, 1980).

Investigations comparing the motor performance of various ethnic origins have yielded conflicting and inconclusive results. Few investigations have observed significant differences between ethnic origins relative to gross motor performance measures (DiNucci \& Shows, 1977; Kaufman, \& Kaufman, 1973; Stone, 1966). 


\section{Statement of Problem}

In this study the sit and Reach Test and the Leighton Flexometer were employed to measure flexibility. Though the SRT is used nationally to test children's low back flexibility, it does not distinguish between the contributions of anthropometric factors to total performance (Cornbleet \& Woolsey, 1991; Jackson \& Baker, 1986; Kippers \& Parker, 1987). Because of the controversy over what the instruments actually measure, there is a definite need to examine the flexibility testing methods currently being administered. There is also the need to further examine the possible relationships that age, gender, and ethnic origin may have on flexibility because of the varying results reseachers have found when examining these factors.

\section{Statement of Purpose}

The purpose of this study was to determine the effects of age, gender, and ethnic origin on flexibility as measured by the SRT and the Leighton Flexometer.

\section{Hypotheses}

The hypotheses for this study are:

1. A significant age effect will be determined with younger subjects showing greater flexion as measured by the SRT and the Leighton Flexometer. 
2. A significant gender effect will be determined with female subjects showing greater flexion as measured by the SRT and the Leighton Flexometer.

3. No significant difference will be determined between ethnic origins on flexibility as measured by the SRT and the Leighton Flexometer.

4. A strong correlation will be determined for flexion as measured by the SRT and the Leighton Flexometer.

Delimitations

This research was delimited to the following:

1. measurement of flexibility using the Leighton Flexometer and the SRT,

2. 265 male and female subjects,

3. elementary and junior high school subjects,

4. six to fourteen year-old subjects,

5. subjects from three ethnic origins, Hispanic, Caucasian, and Asian, and

6. subjects performing a flexibility task.

\section{Iimitations}

The following limitations were noted for this research: 1. Differences in psychological, physiological and social parameters of children reduced the generalizability of these data to the general population. 
2. Experimental conditions, though carefully controlled, were not ideal and may have affected the performance and the motivation of subjects completing the flexibility task. 3. Subjects were expected to perform to the best of their ability, however, (a) there may not have been sufficient motivation for the youngster to perform at maximum level, or (b) There may not have been an accurate determination by the researcher of subject's maximum effort.

4. Subjects were tested in a multi-purpose room. While this space allowed the investigator control of potential visual distractions during testing, normal school functions may have distracted subjects during performance.

5. There may have been measurement error because of possible differences in anthropometric, gender, or age-related factors with ethnic origins as measured by the Leighton Flexometer.

\section{Definitions}

The following terms are defined for the purpose of this investigation:

Elexibility: "the capacity to move body segments operating around a specific joint through a normal range of motion" (AAHPERD, 1984, p. 20). 
Leighton Flexometer: "a circular scale used to measure degrees of motion with a weighted pointer controlled by gravity attached to the center" (Ekstrand, Wiktorsson, Oberg, \& Gillquist, 1982, p. 171).

Sit and Reach Test: "fitness test that evaluates the abdominal and lumbar musculoskeletal function" (Jackson \& Baker, 1986, p. 183).

Lumbar Vertebrae: "five vertebrae of the human skeleton that form a stable and mobile axis and are essential to normal human posture and activity" (Twomey, 1987, p. 2). 
Chapter 2

REVIEW OF LITERATURE

Introduction

In this chapter the basic anatomy of the human lumbar spine is reviewed. The section on anatomy is divided into general lumbar anatomy, muscular control, and range of motion of the lumbar region. The instruments that are currently being used for measurement of flexibility are also examined. The sections investigating flexibility are divided into current research and instrumentation, research on the AAPHERD Sit and Reach Test, and research using the Leighton Flexometer. Studies on the effects of age and gender on flexibility and motor performance are also reviewed. Also included is a section on studies of ethnic origins and motor performance. Finally, a summary of the chapter is presented.

\section{Anatomy of the Lumbar Spine}

The anatomy of the lumbar spine provides mobility for the back. It is also the structural link between the thorax and the pelvis, and transmits weight to the lower extremities. Since there are no ribs attached, the lumbar spine has a relatively wide range of motion (Hoppenfeld, 1976).

The vertebral column is formed by a series of thirtythree vertebrae, five of which are the lumbar vertebrae. The 
bodies of the movable vertebrae are separated by intervertebral discs. The lumbar vertebrae are more massive and heavier than the other vertebrae, allowing greater mobility. To maintain forward flexion and a upright stance, the discs must have full and free compliance for movement and the spine needs a muscle-joint alliance (Twomey \& Taylor, 1987). When the vertebral column is stripped of its muscles, it is unstable. The muscles which support the spine stabilize it posturally and control the vertebral motion during movements of the whole column (Headley, 1990) (See Figure 1).

\section{Muscular Control of the Lumbar Region}

The lumbar back muscles exert considerable control over active ranges of lumbar movement while the erector spinae and multifidis are responsible for all movements that are gravity assisted. Thus, trunk flexion in standing or sitting is controlled by an eccentric contraction of these muscle groups. The spine extensors and the iliopsoas muscles exert movement by extending the spine by direct action. In comparison to the joints of the extremities, there is relatively little motion in the individual (facet) joints of the lumbar spine. Flexion primarily involves motion in the hip. Only a small amount of movement actually takes place in the spine itself. In the majority of body activities, 
movements of the lumbar spine and hip go together (Troup, 1979).

The gluteal and hamstring muscles provide flexion for the spine by exerting the biceps, femoris, semimembranosis, and semitendinosus. This muscle bulk is carried along the length of the femur. The stretching ability of the muscles of the lower back and hamstrings is an indicator of the flexibility of this area (Johnson, \& Lavay, 1988). The abdominal muscles when flexing the spine approximate the distance between the thoracic cage and the pelvis (Finneson, 1973) (See Figure 2).

Range of Motion of the Lumbar spine

The bodies of the lumbar vertebrae are separated by elastic intervertebral discs. The disc's range of motion between vertebrae is determined by the disc's resistance to distortion and partly by the angle and size of the articular surfaces between the processes. Vertebral motion is greatest where the discs are thickest and the joint surfaces largest (Hoppenfeld, 1976).

The movements of the lumbar spine are (1) flexion, (2) extension, (3) lateral bending, and (4) rotation. In comparison to the joints of the extremities, there is relatively little motion in the individual facet joints of 
the lumbar spine. Major motion, such as flexion, primarily involves motion in the hip (Hoppenfeld, 1976).

Flexion in the lumbar spine involves relaxation of the anterior longitudinal ligament and the stretching of the supraspinal interspinal and posterior longitudinal ligaments. Flexibility is limited by the size of the vertebral bodies. Extension of the lumbar region stretches the anterior longitudinal ligament and relaxes the posterior ligaments. Thus, lateral bending and rotation must occur in conjunction, because the lumbar range is limited by the surrounding Iigaments (Hoppenfeld, 1976). 
Figure 1. Lateral view of vertebral column.

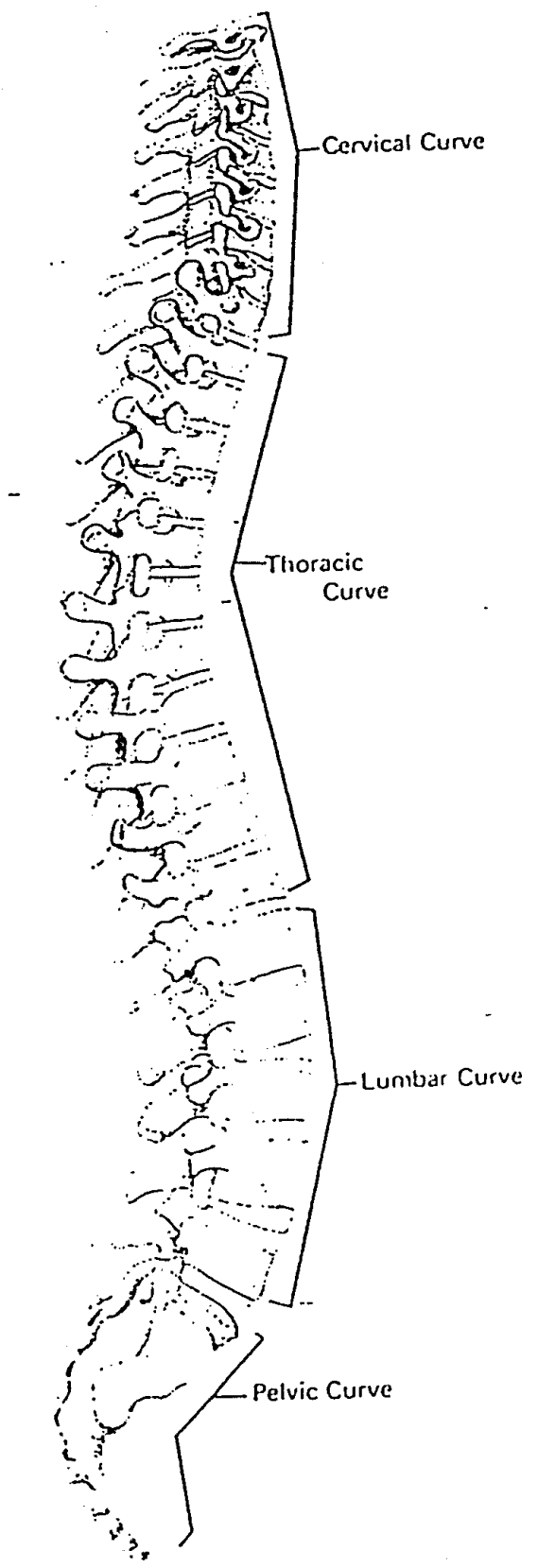

NOTE: From Low Back Pain (p.6) by B. Finneson, 1973, J.B. Lippincott Co. reprinted by permission. 
Figure 2. Muscles involved in flexion and extension.

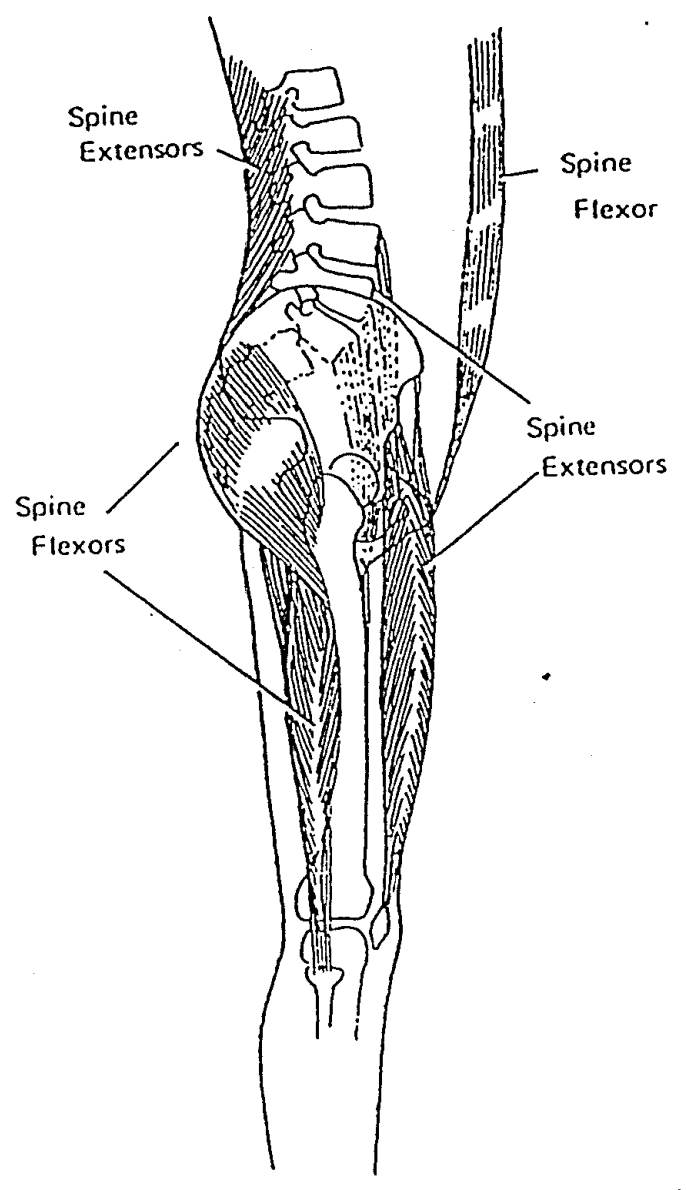

NOTE: From Low Back Pain (p.180) by B. Finneson, 1973, J.B. Lippincott Co. reprinted by permission. 
Research and Instrumentation of Flexibility

Objective methods of externally measuring the motion and curvature of the lumbar spine are important in assessment of spinal mobility . Many methods of measuring the range of motion of the spine have been investigated. Past experimental work described existing measuring devices and systems of measurement for flexibility (Broer \& Galles, 1958; Cureton, 1941; Kraus \& Hirschland, 1954; Scott \& French, 1959).

Cureton (1941) used sliding wood calipers to measure trunk flexion, extension, and shoulder flexibility. In the trunk-flexion test, the subjects began in a supine lying position and bent forward. The score was the distance from the chin to the table. The test-retest reliabilities for this particular test were .958. Frost, Stuckey, and Smalley (1982) and Kraus and Weber (1945) measured total range of motion in flexibility as the distance from the fingers to the floor. The Kraus and weber test (1945) for flexion of the lumbar spine included a pass-fail test for touching the toes. Buxton (1957) extended the Kraus and weber test to include a more discriminating scoring method in which the subjects stood on a six-inch high bench. Downward reach was measured on a scale marked in half-inch intervals. Buxton reported a reliability of .95 for subjects six to fifteen years of age. Other research using this toe-touch test method included 
Scott and French (1959) and Broer and Galles (1958) who reported reliabilities of .93 and .973 , respectively. Both studies examined college women.

In the examination of the toe-touch test, the validity in assessing mobility of the vertebral column was criticized because of the involvement of hip movement (Clark, 1975; Hart, Strickland, \& Cliffe, 1979). In a study by Kippers and Parker (1987), measurements were taken from lateral photographs of each subject standing in the erect and flexed lumbar positions. Subjects were randomly selected males $(n=16)$ and females $(n=17)$. Reliability of the vertebral flexion, as determined by a Pearson product-moment testretest correlation, was .97 . The toe-touch test was determined to be unsuitable to measure vertebral mobility because of the partial correlation coefficient (-.64) between the vertebral flexion and limited hip flexion. But, the use of the toe-touch test as an indicator of hip flexion when the knees remain extended was found to be valid, reliable, and easy to use for showing changes in total motion for an individual over time. However, the measurements are controversial when used to measure regional spinal motion because of the involvement of hip movement and of differences in arm length and leg length among individuals (Frost et al., 1982) • 
Recently, the flexible ruler has been used in research to measure flexibility. In an investigation to examine the intratester and intertester reliability of lumbar measurements using this device, two groups of 40 volunteers were selected. A flexible ruler was used to obtain tracings of the lumbar lordosis of each subject. Small adhesive markers with a horizontal line drawn through the center of them were used to mark the spinous processes L3 and S2. A straight ruler marked in one millimeter increments was used to measure the tracings. Final data were used to calculate the lumbar angle. Results showed that intertester reliability was poor, with intraclass correlation coefficients of .41 for subjects without lower back pain (Lovell, Rothstein, \& Personius, 1989).

In a simliar study by Hart and Rose (1986), the flexible ruler was tested for reliability and validity for the determination of the curvature of the lumbar spine in forward flexion and normal quiet standing. The ruler was applied to the skin over the lumbar spines of 23 normal adults and an angle in degrees between two spinous processes ( $\mathrm{L} 1$ and $\mathrm{S} 2$ ) was calculated. Intratester test-retest reliability was excellent for the two separate measures of spinal positions $($ ICC $=0.97, n=89)$. The validity of the flexible ruler measurements was also excellent when compared to two different measurement techniques from a limited number (6) of 
subject roentgenographs. The flexible ruler was determined to be a reliable and valid measurement technique for quantifying lumbar postures.

The lumbar spondylometer is another instrument that measures flexibility. Since its base rests on the sacrum, the measurement is not invalidated by hip motion (Farrell, 1982). The cushions of the lumbar spondylometer rest on the dorsal surface of the sacrum with the top cushion at the level of S1, and the distal end on $\mathrm{L} 1$. The tester reads off the initial starting position in degrees, asks the subject to fully extend, and then reads the new position in degrees. The subject then moves through the full-range of flexion. Thus, flexion and extension are recorded. The entire process takes less than two minutes to administer and record and appears to be reliable and useful in clinical measurement (Hart, Strickland, \& Cliffe, 1979; Reynolds, 1975; Twomey, \& Taylor, 1987).

Several other measurement techniques have been studied for measurement of flexibility. In a study that examined the measurement of trunk flexibility in normal subjects, three clinical methods were reproduced; the fingertip-to-floor test, a modification of the schober's skin distraction test, and the Loebl Flexion and Extension test. Subjects were 50 volunteer males and females, all of whom were healthy adults with no history of appreciable back pain or musculoskeletal 
disease. Each subject was studied on three separate days within a 7-day period. An identical testing sequence was followed for all subjects. First, the fingertip-to-floor test was administered. Then, the Schober skin distraction method and finally the Loebl Flexion and Extension tests were administered. The fingertip-to-floor test was measured with the subjects standing barefoot, heels on the floor, feet shoulder width apart, and knees straight. Subjects were asked to bend forward maximally as if to touch their toes and to maintain this position for 15 seconds. The distance from the tip of the finger to the floor was measured to the nearest $1 / 2$ centimeter. Trunk flexion was measured with the use of a modification of the Schober's skin distraction method. With the subject standing erect, but relaxed, a point was drawn with a skin marker at the spinal intersection of the line joining at the sacrum. Subjects were then asked to bend forward as they did for the fingertip test. The distance between the marks ten centimeters above and five centimeters below S-1 was measured. This value minus 15 centimeters represents flexibilty. On the assumption that the curvature of a spinal segment can be determined by the angle formed by the tangent of another point on the curve, Loebl (1967) described a method of measuring four spinal segments with the use of an inclinometer. Motion can be measured across any segment by calculating the differences 
between angles measured while the back is flexed. The examiners recorded the following mean coefficients of variation of interexaminer and intraexaminer reproducibility of results: fingertip-to-floor, $83 \%$ and $76 \%$; flexibility (Moll), 6.3\% and 6.6\%; and Loebl flexibility, $9.6 \%$ and $13.4 \%$. Although the reproducibility of the fingertip-to-floor and the Loebl test was poor, the Moll flexibility test had good reproduciblity. The findings that interexaminer and intraexaminer reproducibilities were similar suggests that subject-related factors, such as day-to-day variation in motivation and effort and intrinsic errors in measurement, are the principal variables that affect reproducibility (Merritt, McLean, Erickson, \& Offord, 1986).

Several problems have existed when using radiographic and photographic methods to measure flexibility. The radiological methods are of little value considering both the errors which arise and the hazards of radiation. Radiological equipment can also be unreliable for accurate measurements in the lumbar region. A scanographic technique may be applied if the hazards of radiation were reduced (Troup et al., 1976). Photographs are also expensive, and studies have not demonstrated a high degree of validity for this method (Burdett, Brown, \& Fall, 1986; Lovell, Rothstein, \& Personius, 1989) 
Sit and Reach Test

In 1980, the American Alliance for Health, Physical Education, Recreation and Dance (AAHPERD) presented a physical fitness test battery that was designed to measure components of fitness which related to healthier living and the therapeutic values of exercise (AAHPERD, 1980). Due to the health related problems of low back pain, one component of the test was abdominal and low back musculoskeletal function. The Sit and Reach Test was used to measure flexibility. The test was selected because of its feasibility, reliability, logical validity, and reported criterion-related validity (AAHPERD, 1980; Wells \& Dillion, 1952 )

Researchers have previously examined the validity of the SRT with the principal concern being the possible extraneous relationships that might exist between anthropometric variables and performance on the test (Broer \& Galles, 1958; Cornbleet \& Woolsey, 1991). These variables included varying arm, trunk, and leg length or inflexibility of the spine. Though the SRT is performed nationally on children as an indicator of flexibility in the low back and hamstring muscles, the score does not distinguish between the contributions of the low back and hamstrings to the total performance. Cornbleet and woolsey (1991) researched these factors by examining the relationships between pelvic tilt 
in long sitting (an indirect measure of hamstring length) and low back flexibility. Subjects were 123 students, ranging from 5-11 years. Each subject was seated on the floor and instructed to reach forward maximally with their knees fully extended and ankles in a neutral dorsiflexion. The score for the SRT was obtained and the final pelvic tilt angle was measured using an inclinometer placed over the sacrum. Although the correlation between SRT scores and pelvic tilt angle was statistically significant $(r=.80, \underline{p}<.05), 17 \%$ of the subjects had erroneous scores due to excessive posterior pelvic tilt or anthropometric factors (varying leg, arm or trunk length). Based on these results, the score on the SRT should include measurements of pelvic tilt and the contribution of the hamstrings to the total performance. Jackson and Baker (1986) conducted a sirnilar study that examined the relationships between the SRT and criterion measures of hamstring and low back flexibility in females between the ages of 13 and 15. The SRT was administered utilizing procedures outlined in the AAHPERD Health Related Fitness Manual (1980). For hamstring flexibility, a maximum passive straight leg raise was elicited from each limb of the subject while a Leighton Flexometer was attached to the leg. A skin distraction method was utilized for measurement of back flexibility. The criterion-related validity of the SRT as a measure of hamstring flexibility received a moderate 
correlation $(r=.64)$ between the SRT and the measure which utilized the Leighton Flexometer, but a low correlation $(I=.28)$ with low back flexibility. They concluded that the SRT and hamstring flexibility were not a valid field test of low back flexibility. This result was in general agreement with the Harris (1969) report of the specificity of flexibility. If low back flexibility is measured, then a specific test of that component should be used.

In a similar study, Jackson and Langford (1989) replicated the previous study of Jackson and Baker (1986) to find if the results could be extended to adults. The subjects included 52 males and 52 females with ages ranging from 20 to 45 years. Administering the same tests, the SRT, the Leighton Flexometer for hamstring flexibility, and the skin distracton method, results showed that there was an extreme consistency between flexibility results for the female sample and the previous report on teenage females. The SRT appeared to possess a excellent validity as a measure of hamstring flexibility $(x=.86)$, but was not a valid measure of low back flexibility $(I=-.11)$. The results for the male sample were also inconsistent with the previous results and the results of the present female sample. The SRT possessed excellent criterion-related validity ( $I=.89$ ) as a field test of hamstring flexibility, and was moderately related ( $I=.59$ ) to low back flexibility. This was a 
significantly higher measurement in hamstring flexibility for females. Also, no significant differences were found between females and males for low back flexibility, which was consistent with past literature (Kippers \& Parker, 1987). The SRT validity in assessment of mobility of the vertebral column has also been criticized because of the involvement of hip movement (Kippers \& Parker, 1987). The purpose of this study was to determine the relationships between the fingertip-floor distance (FFD) and both the pelvic and vertebral components of trunk flexion. The FFD was recorded using a 35 millimeter camera mounted on a tripod. The erect position served as a reference from which calculations of the various trunk segments were taken during performance of the toe-touch test. During trunk flexion, the hips moved posteriorly and altered the angle between the lower limb and an external horizontal reference. The long axis of the thigh was used as a reference for trunk and pelvic angle measurements. The positions of anatomical features were marked on the skin, and all of these landmarks on the photographs were digitized with calculation of angles between body segments. Their findings indicated that the standing toe touch is highly related to trunk and hip flexion, but not to vertebral flexion $(x=.10)$. The contribution of hip flexion to trunk flexion is greater than that achieved by vertebral flexion because the pelvis rotates 
about the gross center of sagittal motion, the hip joint, whereas vertebral movement occurs further from this point at the thoracolumbar region. These results have direct implications for the SRT because the standing toe touch test has a similar measurement protocol from the standing position.

Extensive cross-sectional data on SRT scores at various ages have been obtained through the Canada Fitness Survey (Fitness and Lifestyle Research Institute, 1983), but the extent the changes of scores for this test reflect the general loss of flexibility with aging is unclear. In a study by Shephard, Berridge, and Montelpare (1990), flexibility was examined with the purpose of identifying common flexibility factors and the generality of SRT scores relative to age and gender-related differences of flexibility seen at other major joints. Subjects included ninety females and males aged 45-75 years. The technique used for the SRT followed the Canada Fitness Survey protocol which is similar to the AAHPERD's protocol for the SRT. Flexibility of other joints were measured by a simple goniometer, the Leighton Flexometer. Observations included head rotation, shoulder hyperextension, internal and external rotation of the shoulder, hip flexion, ankle plantar flexion, and ankle dorsiflexion. The females scored significantly better than the males on the SRT $(\underline{p}<.002)$, and had greater hip 
flexibility $(p<.04)$, and greater internal rotation of the shoulder $(\mathrm{p}<.05)$. In terms of reliability, the present results suggested that the SRT provides more reproducible data than the alternative option of goniometer measurements. The study also highlighted the difficulty of making goniometer measurements in an older and less active population. Cross-sectional analyses of the SRT scores only showed a trend to within-sample effect of aging when an agegender interaction term was introduced, but age-related changes were more clearly demonstrated for the head and shoulder joints (Shephard, Berridge, \& Montelpare, 1990).

\section{Leighton Flexometer}

To assist in measuring flexibility, the Leighton Flexometer was devised. This instrument consists of a weighted $360^{\circ}$ dial and pointer that operates freely and independently; its movement is controlled by gravity. The instrument records range of movement in degrees while in any mobile position which is $20^{\circ}$ or more off the horizontal. In using the instrument, the flexometer is strapped to the segment being tested. When a movement is made, the pointer is then locked at the position. Then, the dial reflects the number of degrees through which the individual has moved.

To facilitate the accurate use of the instrument, standard starting positions were established for each 
movement. The movement then takes place to the finishing position. The mechanics of the instrument are based on the fact that gravity always pulls the weighted end of the needle downward during the execution of the movement. Its validity as a device to measure flexibility of ranges of motion is based upon the condition that most of the bending done by an individual during a movement takes place around the joints of the segments. This instrument has met the criteria of validity, objectivity, and reliability in that: (a) all movements measured corresponded to the recognized segmental movements of the body; (b) a correlation coefficient between the first and second measurement was derived for each of the 30 measures; recorded they ranged from .913 and .996; (C) all measures were recorded in degrees of a circle; and (d) flexibility measures were compared for similarity using the existing differences between means to determine $t$ value. No significant difference was found between these means. This system of measurement was sufficiently objective and reliable when measured by different individuals (Leighton, 1955) •

This system of measurement was also found to be efficient in collection of data for either individuals or groups. The average time required for the complete measurement of each subject was approximately twenty minutes. The procedure was neither too complicated nor technical (Leighton, 1942). 
Gender, Age, and Flexibility

The development of gender and age differences in physical activity has been reported for many types of tasks (Eaton \& Enns, 1986; Hyde, 1984; Maccoby \& Jacklin, 1974; Nelson, Thomas, \& Nelson, 1986; Thomas \& French, 1985). These studies reviewed gender differences in cognitive, affective, and motor performance. Findings have also indicated that many types of gender differences may be age related. Reliable gender differences have been reported in large-scale meta-analyses for aggression, motor activity level and motor performance (Eaton \& Enns, 1986; Hyde, 1984; Morris, Williams, Atwater, \& Wilmore, 1982; Nelson, Thomas, \& Nelson, 1986; Thomas \& French, 1985). In the two metaanalyses of motor performance activity, gender differences were related to age at least through adolescence. Suggested for these relationships are that nearly all the gender differences prior to puberty in health-related physical fitness are due to the different treatment and expectations our society has for females and males. After puberty, a biological-environmental interaction appears to be the best hypothesis for the increasingly large effects noted in motor performance tasks (Thomas \& French, 1985). These studies have also shown that gender differences increased with age. Thomas and French (1985) reported that gender differences in 12 of 20 motor performance tasks were found to be related to 
age. A meta-analysis was conducted to examine gender differences in motor performances during childhood and adolescence. Motor performance was defined as the outcome of movement. In this study, motor performance was delimited to include fundamental skills; basic abilities such as balance and fine eye-motor coordination; motor fitness items such as agility, arm strength, flexibility, and sit-ups; and information-processing responses such as reaction time, pursuit rotor tracking, and anticipation timing. specifically excluded were cardivascular items such as distance runs, step tests, and laboratory tests. Data were compiled from 64 studies yielding 702 effect sizes based on 31,444 subjects; 15,926 were males and 15,518 were females. Effect sizes were calculated for all male-female comparisons at each age level for motor performance tasks reported. An effect size was obtained for a given task at a specific age by subtracting the mean for girls from the mean for boys and dividing the standard deviation. When the mean for the boys represented better performance, the effect size was positive. When the girls averaged a better performance, the effect size was negative (Hedges, \& Olkin, 1985). Age was regressed on effect size, and the relation was significant for 12 of 20 (60\%) motor performance tasks. The data did not support the notion of uniform development of gender differences in motor performance across childhood and adolescence. 
Several types of age-related curves were also found in a meta-analysis study by Thomas and French (1985). Age ranges were from three to twenty years. The curve for the throwing task being the most distinctive. Five of the tasks followed a typical curve for gender differences across age. For eight tasks, gender differences were not related to age, and effect sizes were small. Six of these tasks had effects sizes below .40: agility, anticipation timing, arm hang, fine eye-motor coordination, reaction time and flexibility. Environmental factors of differing expectations, practice, and gender indentification are suggested for these effect sizes. The effect sizes also remained moderate across the elementary school years for four of the tasks, but increased during elementary school for sit-ups. The females, upon reaching puberty, appeared to reduce the difference on the dash, grip strength, and the shuttle run, but not in the long jump and sit-ups. When the males reached puberty, all five tasks were influenced in the same way; they increased their advantage over females rapidly until differences 1.5 and 2 standard deviations units at seventeen years of age were noted. Females, on reaching puberty, closed the performance difference on five tasks: dash, sit-ups, long jump, grip strength, and the shuttle run. When males reached puberty, their increase in size and muscle tissue were dramatically 
reflected in better performance across all five tasks (Thomas \& French, 1985).

Around puberty, biology plays an important role in the development of gender differences, since hormonal changes result in increased muscle mass in males and increased essential fat in females. However, differences can be influenced by environmental experiences, since females are less likely to participate in activities that promote the development of motor skills associated with sport (Thomas \& French, 1985).

The data available on very young children is reported as the degree of motor activity. In a review and meta-analysis of gender differences in motor activity, Eaton and Enns (1986) reported a mean effect size of .49 across 127 studies of motor activity in children. Male babies were significantly $(p<.001)$ more active than female babies $(E S=.29)$, and the effect size increased to .44 for preschoolers and .64 for older chldren. The differences in motor activity as early as infancy suggest some hereditary influence. The findings included an effect size of .33 for six prenatal studies. Effects of social influences that magnify hereditary differences are suggested by the gradual increase in effect sizes across ages (Eaton \& Enns, 1986).

In a study by Morris et al. (1982), the relationship of age and sex to the performance of $3,4,5$, and 6 year-olds on 
seven motor performance test items were examined. These tests were selected to represent the fundamental motor skills; specifically, running, jumping, throwing, catching, and balancing. These tests consisted of balance, scramble, catching, speed run, standing long jump, tennis ball throw for distance (three to four year-olds), and the softball throw for distance for the five and six year-olds. Subjects were 269 Caucasian males and females. The seven test items were repeated by all subjects on a second testing day so that variability in performance might be examined. A Pearson Product-Moment correlation was used to determine the extent that the subjects maintained the same relative positions. Also, a t test was employed to evaluate if a significant difference was determined. Although significant age and sex differences were found on most of the motor tests, performance was generally related more to age than was gender. Overall, change with age was fairly linear except for balancing and a general tapering in improvement in the five to six year-old category. On the tests of throwing and balancing, gender was as important as age, in its relationship to performance. Males were superior to females at all ages on the throwing tests; females were superior to males at age six on the balance test.

In another study on gender differences, Nelson, Thomas, and Nelson (1986) examined the influence of biological and 
environmental variables on the differences between the throwing performance of five year-old males and females. The subjects were 100 females and males at five years of age at the time of measurements. Approximately half of the subjects were Caucasian $(\mathrm{n}=41)$ and half Black $(\mathrm{n}=59)$. The subjects were evaluated on two components of throwing form, trunk rotation and foot action; eight biological characteristics (height, weight, body mass index, ponderal index, sum of four skinfolds, body diameters, arm and leg girths); somatypes; and four environmental characteristics, older brother or sister, presence of adult male, and playing with older children. Results indicated that males threw farther than females and exhibited more mature form. Males also had greater joint diameters than females, a smaller sum of skinfolds, and more estimated arm muscle. Females throwing performance was only $57 \%$ that of males. In sum, while differences in most motor performance tasks between males and females prior to puberty have been attributed to environmental factors, some of the differences in throwing performance appear to reflect biological characteristics (Nelson, Thomas, \& Nelson, 1986).

Ross and Gilbert (1985) and Ross, Pate, Lohman, and Christenson (1987) reported results of the National Children and Youth Fitness Study, which was designed to assess the health-related physical fitness of males and females in the 
United states. These two studies included results from a national sample of over 13,000 children from 6 to 18 years of age. Data were collected on the performance variables of the mile run, sit-ups, chin-ups, and the SRT. Physical characteristics and environmental variables were determined by a survey.

Thomas, Nelson, and Church (1988) recently completed a secondary analysis of the National Children and Youth Fitness Study. This data identified where gender differences occurred in health-related physical fitness and what physical and environmental characteristics were related to the observed differences. The SRT performance was considerably different from other health-related physical fitness tests with girls' performances better than boys' performance at all ages. Effect sizes were -.25 to -.63 from 6 to 11 years of age. From 12 to 16 years of age, effect sizes increased -1.0 ; then after 16 years of age, effect sizes returned to -.5 standard deviation units. None of the physical or environmental characteristics were reliably related to SRT performance.

In a study by Docherty and Bell (1985), the Leighton Flexometer was utilized to measure the relationship between selected anthropometric measures of linearity and measures of flexibilty relative to age and gender. Five measures of limb and trunk length were taken in addition to three linear 
measures of flexibility and six measures of angular displacement using the Leighton Flexometer. Two-way ANOVAS in all measures of limb and trunk lengths revealed predictable growth profiles for both ages and gender. The Correlations were .82 for the males and .84 for the females. Relative to age, the following correlations were yielded: .83 at six years, .77 at nine years, .77 at twelve years, and .87 at fifteen years. For trunk extension and flexion, the females showed higher levels than the males $(\mathrm{p}<.01)$. For the SRT, the females again showed higher levels than males with a significant age by gender effect (Docherty \& Bell, $1985)$

In an Illinois study on fitness, the fitness levels of children participating in a movement education (ME) program were compared to the IIIinois fitness norms. The AAHPERD Health-Related Fitness test was administered to children ages 7-12 for three consecutive years. Scores for sit-ups and the SRT showed that the 9 and 11 year old ME males had more abdominal strength than the females and the 11 and 12 year old ME females, less flexibility than the males (Bischoff \& Lewis, 1987). Also, the flexibility of 10, 11, and 12-yearold males slightly declined in comparison to the percentage of 12-year-old females at the 50th percentile. Flexibility levels also decreased with reduced activity levels (Bischoff \& Lewis, 1987). 
Motor Performance and Ethnic Origins

Investigations comparing the motor performance of populations from various ethnic origins have yielded conflicting and inconclusive results (DiNucci \& Shows, 1977; Kaufman, \& Kaufman, 1973; Ponthieux \& Barker, 1965; Stone, 1966)

In a study by DiNucci \& Shows (1977), the effects of age and ethnic origin on Black and Caucasian females were evaluated. Ninety female subjects, ages ranging from six to eight years, were administered 28 test items measuring speed, muscular power, agility, flexibility, balance muscular endurance, and cardiorespiratory endurance. Following the completion of the testing program, the data were statistically analyzed. Few significant differences were observed between adjacent ages, but eight year old females were significantly superior to the six year old subjects on most motor performance variables. For ethnic comparisons, no significant differences were noted for measures of flexibility, muscular endurance, speed, balance, or muscular power. The Black subjects were significantly superior on two measures of agility while the Caucasian subjects performed significantly better on the shuttle run and grip strength. Analysis of the ethnic differences support the findings of Hutinger (1959), and Barker and Phonthieux (1965) who found Black females superior to Caucasian on measures of speed. 
Few investigations have found significant differences in favor of Caucasian female subjects relative to gross motor performance measures (DiNucci \& Shows, 1977; Kaufman et al., 1973; Stone, 1966).

In a study by Ponthieux and Barker (1965), possible relationships of ethnic origin to motor abilities and physical fitness were analyzed by administering the AAHPER Youth Fitness Test. Subjects consisted of the Black and Caucasian population. The subjects studied were 633 children, with ages ranging from 10-12 years. Distribution of subjects by sex and ethnic origin showed the subjects to be $20 \%$ Black, and $80 \%$ Caucasian. The findings, using point biserial coefficients of correlation, indicated that the Black males exceeded the Caucasian males significantly in five components of physical fitness (pull-ups, broad jump, 50-yard dash, softball throw, and 600-yard run-walk) as measured by the AAHPER Youth Fitness Test, while there were no significant differences between their performances on the other two measures (sit-ups and shuttle run). The Black females surpassed the Caucasian females significantly on four measures; the Caucasian females surpassed the Black females on two (pull-ups and sit-ups); and there were no significant differences in the female performance on the one remaining test (shuttle run). The findings also indicated relationships between ethnic origin and some measures of 
physical fitness, but these generally favored the Black subjects over the Caucasian subjects, especially the males (Pontheiux \& Barker, 1965).

Research exploring the relationship of the differences in speed between Black and Caucasian children, as measured by the 35-yard dash, was conducted by Hutinger (1959). The study examined 792 Black and Caucasian subjects with ages ranging from nine to eleven years. Each subject was administered two trials of the the 35-yard dash with the fastest trial being recorded. Differences in the mean scores administered indicated that the Black children were superior in running speed to the Caucasian children at all age levels. Suggested for this difference was that the Black children had a faster reflex, which correlated highly with the faster times recorded in the 35-yard dash (Hutinger, 1959).

Other research concerning motor performance of Black and Caucasian children has also indicated superior performance among the Black elementary age children (Hutinger, 1959; Malina, 1968; Ponthieux \& Barker, 1965). Socioeconomic status has been suggested as the variable that accounts for ethnic differences in motor performance. Children from different home and socioeconomic environments have experiences in different recreational games and facilities (Scott, Ferguson, Jenkins, \& Cutter, 1955). Research on the ethnic and social class issues report several studies that 
found Blacks to be slightly superior to Caucasians even when social class was equal (Malina, 1968). In contrast, DiNucci and Shows (1977) found few significant differences in the scores of Blacks and Caucasians while administering a variety of physical fitness and motor fitness test items.

In a study by Lee (1980), the relationship between maternal child-rearing practices and the development of motor skill proficiency in Black and Caucasian children from similar socioeconomic backgrounds was examined. Subjects were tested using a running and a jumping task and the Orthner modification of the Porter Authoritarian Control Scale (Orthner, 1969). During administration of the orthner scale, the parent selected one of five multiple choice statements which followed each of the 58 items on the scale. For the motor performance tasks, each subject was tested individually using two motor performance tasks, a standing broad jump and a 30-yard dash. Test-retest reliability estimates for the jumping and running tests were .72 and .84 , respectively. The orthner scale was administered to measure the degree to which a parent attempted to restrict the autonomy and mold the attitudes of a child. This instrument was designed to discriminate between authoritarian and nonauthoritarian parents. The results showed the superiority of Black over Caucasian children and of children reared by nonauthoritarian mothers over children reared by 
authoritarian mothers in the two motor performance tasks administered (Lee, 1980).

\section{Summary}

The major purpose of this study was to examine the effects of age, gender, and ethnic origin on flexibility as measured by the SRT and the Leighton Flexometer.

In 1980, the American Alliance for Health, Physical Education, Recreation and Dance (AAHPERD) presented a physical fitness test battery that was designed to measure components of fitness which related to healthier living and the therapeutic values of exercise (AAHPERD, 1980). The SRT was developed to measure low back flexibility. Numerous studies have researched different factors that were related to the SRT. These have included pelvic tilt in long sitting, hamstrings contribution, and the involvement of trunk and vertebral flexion. All these studies have found some sort of discrepency in the measurement of flexibility using the SRT or the Leighton Flexometer (Cornbleet \& Woolsey, 1991; Jackson \& Baker, 1986; Jackson \& Langford, 1989; Kippers \& Parker, 1987). The SRT validity in assessment of the mobility of lumbar region of the vertebral column has also been criticized because of the involvement of hip flexion (Kipper \& Parker, 1987). 
The lumbar spine provides the mobility for the back. It also furnishes support for the upper portion of the body and transmits weight to the pelvis and lower extremities. The movements of the lumbar spine are flexion, extension, lateral bending and rotation (Johnson, \& Lavay, 1988).

Because so many segments are involved in movements of the spine, an exact determination of spinal mobility is difficult though a number of methods have been devised and used. These devices and test methods have included flexible rulers, lumbar spondylometers, radiographs, specialized goniometers, skin distraction methods, fingertip-to-toe tests, plus many others. Many of these techniques have not demonstrated a high degree of validity or reliability consistently (Burdett, 1986; Hart \& Rose, 1986; Kippers \& Parker, 1987; Lovell et al., 1989; Troup et al., 1976). To assist in the effort to measure flexibility, the Leighton Flexometer was devised. In using the instrument, the flexometer is strapped to the body segment being tested. The mechanics of the instrument are based on the fact that gravity always pulls the weighted end of the needle downward during execution of the movement. The instrument will record movement which is $20^{\circ}$ or more off horizontal.

In a study by Docherty and Bell (1985), the Leighton Flexometer was utilized to measure the relationship between anthropometric measures of linearity and measures of 
flexibility relative to age and gender. Five measures of limb and trunk length were taken in addition to three linear measures of flexibility and six measures of angular displacement using the Leighton Flexometer. Females showed greater flexibility than the males with a significant age by gender effect.

Numerous studies have researched the development of gender and age differences with low back flexibility and motor performance (Harris, 1969; Hyde, 1984; Maccoby, 1974; Thomas, et al., 1988). Conclusions of these studies have shown that males perform better on most fitness tasks, with the exception of flexibility, where females performances were better at all ages (Docherty \& Bell, 1985; Ross \& Gilbert, 1985; Thomas et al., 1988). Findings have also indicated that gender differences may be age related. Reliable gender differences have been reported in large-scale meta-analyses for aggression, motor activity level, and motor performance (Eaton \& Enns, 1986; Hyde, 1984; Thomas \& Erench, 1985).

In the two meta-analyses on motor performance, gender differences were related to age at least through adolescence. Thomas and French (1985) reported that gender differences were small or nonexsistent in 19 of 20 motor tasks for children at three years of age. However, they found relatively large gender differences in throwing as early as age three. In addition, males were observed to be more 
active than females even in infancy (Eaton \& Enns, 1986). These findings suggested that heredity may be involved in the development of gender differences (Thomas \& Thomas, 1985). Around puberty, biology plays an important role in the development of gender differences, since hormonal changes result in increased muscle mass in males and increased essential fat in females. However, differences can be influenced by environmental experiences, since females are less likely to participate in activities that promote the development of motor skills associated with sport (Thomas \& French, 1985).

Past research comparing the motor performance of Black and Caucasian children found that Black children performed better (DiNucci \& Shows, 1977; Hutinger, 1959; Malina, 1968; Ponthieux \& Barker, 1965). Like gender differences, factors of body composition and physiological variables have been suggested for these differences. Also suggested to play a part, have been the socioeconomic status of the children as a variable that accounts for ethnic differences in motor performances (Lee, 1980; Scott, Ferguson, Jenkins, \& Cutter, 1955)

Hutinger (1959) investigated the differences in speed between Black and Caucasian children and found that the Black children were superior in running speed, as measured by the 35-yard dash. Also researched were the the comparisons of 
Black and Caucasian children in agility and physical fitness. Ethnic differences in physical fitness found Black males exceeded the Caucasian males significantly in five components of physical fitness and the Black females surpassed the Caucasian females on four measures of the AAHPER Youth Fitness Test (Ponthiuex \& Barker, 1965).

In a study that examined Black and Caucasian children from a low socioeconomic area, subjects were tested on a running and jumping task (standing board jump and the 30yard dash). Also tested were the parents who were administered the orthner scale which measures the degree to which a parent attempts to restrict the autonomy and mold the attitudes of a child. Results indicated greater running and jumping skills for children reared by nonauthoritarian mothers. Black children, regardless of the parental style, showed greater skill than Caucasian children in both running and jumping (Lee, 1980).

Investigations comparing the motor performance of various ethnic origins have yielded conflicting and inconclusive results. Few investigations have observed significant differences in favor of Caucasian subjects, as compared to other ethnic origins relative to gross motor performance measures (DiNucci \& Shows, 1977; Kaufman, 1973; Stone, 1966). 
Chapter 3

METHODOLOGY

Introduction

The purpose of this study was to examine the effects of gender, age, and ethnic origin on flexibility as measured by the SRT and the Leighton Flexometer. In this chapter the age, gender, and ethnicity of the subjects involved and the testing location are described. Details are also presented on instrumentation used and the variables involved. Also listed are the testing procedures and the order that they were administered .

\section{Subjects}

Flexibility measures were taken for 265 subjects, 115 males and 150 females, selected from two local elementary schools in San Jose, CA., and a middle school in Sunnyvale, CA. Three ethnic origins (Asians $\mathrm{n}=90$, Caucasian $\mathrm{n}=84$, and Hispanics $n=91$ ) were selected from the six, ten, and fourteen year-old age groups to measure for flexibility. These ethnic origins were related because they were the three most common origins in each school. Subjects were members of physical education classes in which assessment of flexibility is part of the state-mandated fitness test. All data were collected with the permission, supervision, and cooperation of the teacher in charge. Permission was also obtained from 
the respective school district as well as each child's parent or guardian in authority (Appendix B). Subjects known to have injuries that would inhibit flexibility were excluded from the sample. This was determined by a question that was included in the consent letter that provided a general descriptive background of each subject's history of injury, if any, involving their lower back.

\section{Apparatus}

The SRT and the Leighton Flexometer were used to measure each subject's flexibility. The subject's flexibility was the dependent variable, with age, gender, and ethnic origin the independent variables. Flexibility values were measured using two devices. First, a standardized Sit and Reach Box which has a measuring scale where 23 centimeters is at the level of the feet, was employed. The Leighton Flexometer which allows flexibility of the involved joint and musculature to be recorded as degrees of the range of motion was also used (see pp. 29-30 for a complete description of this instrument).

These instruments have been used previously to measure various back movements (Macrae \& Wright, 1969), leg and back flexibility (Wells \& Dillion, 1952), specific joint motions (American Academy of Orthopaedic Surgeons, 1966), and spinal mobility (Hart, Strickland \& Cliffe, 1974). Although in each 
of these studies the Leighton Flexometer ( $I=.913-.996)$ or SRT ( $r=.97$ ) were reported to be vaiid and reliable for the measurement of flexibility, other possible contributing factors, including trunk, arm, and leg length, or possible involvement of hip flexion or pelvic tilt were not analyzed. For a review of the methods used for the Leighton Flexometer, Sigerseth (1978) has presented a comprehensive review of the use of the flexometer as a measurement tool in flexibility assessment.

\section{Procedure}

Subjects were assigned to groups according to their ages. All subjects with appropriate parental consent were tested, regardless of ethnic origin, so no students would feel "left-out" because of their ethnic origin. The two tests were conducted in an equal counter-balanced order to reduce ordering effects. Measurements were administered by the investigator by having one-half of the subjects, in each group, being tested with the SRT first. The other half were tested with the Leighton Flexometer first. All testing was administered in a multi-purpose room or a quiet area that provided the least distraction to the subject.

Five minutes prior to the administration of the tests, each subject performed a cardiovascular warm-up that included a walk/run around the school's blacktop and a brief 
standardized warm-up of lower back stretching. The instructions to the subject included proper positioning and specific examples of the stretches by the researcher. Each subject performed five repetitions of each stretch. Directions were given as described in the following order:

Modified hurdler stretch

"In a sitting position, place the sole of one foot against the inside of the opposite knee. Reach forward with your hand toward the extended foot. Hold for 5 seconds and relax. Keep both knees on the floor" (Fox, Kirby, \& Fox, 1987, p. 131).

Straddle stretch

"With your feet spread wide and your arms folded, bend at the hips, keeping your knees straight but not locked, and reach toward the floor with your elbows" (Fox, Kirby, \& Fox, 1987, p. 129).

\section{Lateral flexion}

"With feet slightly wider than shoulder width, knees bent, extend one arm up and over your head while pulling the other arm across the body. Flex the trunk first to one side and hold 5 seconds, then repeat to the other side and hold until feeling a good stretch in the side, rear shoulder, and 
back. Do not twist the spine" (Fox, Kirby, \& Fox, 1987, p. 128)

Before individual testing began, proper procedures and instructions were explained for each task. The SRT was administered utilizing procedures outlined in the AAHPERD Physical Best Fitness Manual (1988). These included using the sit and Reach $\mathrm{Box}$ and recording the reach measurement in centimeters. Instructions for administering the AAHPERD Physical Best SRT are as follows:

"To assume the starting position, pupils remove their shoes and sit down at the test apparatus with their knees fully extended and the feet shoulder-width apart. The feet should be flat against the end board. The arms are extended forward with the hands placed on top of each other to perform the test. The subject reaches directly forward, palms down, along the measuring scale four times and holds the position of maximum reach on the fourth trial. The position of maximum reach must be held for one second" (AAHPERD, 1980, p. 20)

Instructions for administering the Leighton Flexometer followed the steps of the SRT with the exception of the actual measurement. The Leighton Flexometer was strapped around the torso, slightly below the armpit at nipple height, and the angular displacement in degrees was recorded. 
The sit and Reach Test Box was kept in position for measurement of both tests. Each subject was allowed an additional trial if the knee raised during the four trials on each test. If the subject exceeded a two trial error limit, that subject's data were then excluded from final analysis. Emphasis was placed on holding a static stretch. Ballistic movements were discouraged.

\section{Statistical Analysis.}

Means and standard deviations were calculated for all measures. To examine the effect of age, gender, and ethnic origin on flexibility, a three-way ANOVA ( 2 x $3 \times 3$, gender $x$ age $\mathrm{x}$ ethnic origin) was calculated for each of the two dependent variables. A post-hoc Scheffe' test was calculated where results of the ANOVA were significant. The .05 alpha level was maintained for all comparisons. Also, a Pearson Product Moment correlation coefficient was calculated to determine the relationship between measures derived from the SRT and the Leighton Flexometer on flexibility. 
Chapter 4

RESULTS AND DISCUSSION

The purpose of this study was to examine the effects of age, gender, and ethnic origin on flexibility as measured by the Sit and Reach Test and the Leighton Flexometer. Data were analyzed with the Statview II data analysis. The results are presented and discussed in this chapter.

\section{Results}

Means and standard deviations for all groups are summarized in Tables 1, 2, and 3 as well as presented graphically in Figure 3 .

Specific differences with age were noted with both instruments. Flexibility increased for the SRT but results showed a decrease between the ten and fourteen year-olds for the Leighton Flexometer. The mean scores for each age group for the Leighton Flexometer and the SRT ranged from 24.6 26.8 degrees and $27.4-30.5$ centimeters, respectively (Table 1). When comparing mean scores based on gender, females in all three age groups performed better than their male counterparts as determined by both measuring instruments. The means for the females ranged from 27.91 30.28 degrees \centimeters, and for the males, ranges were from 24.35 - 26.67 degrees lcentimeters (Table 2). Though not significant, differences were noted between ethnic origins 
with the Asians more flexible on both tests than the Hispanics and Caucasians. The Caucasians showed the least flexibile scores on both tests (Table 3 ).

Table 1

Means and Standard Deviations by Age as Measured by the Leighton Flexometer and the SRT

\begin{tabular}{|c|c|c|c|c|c|}
\hline & & \multicolumn{2}{|c|}{ Leighton Flexometer } & \multicolumn{2}{c|}{ Sit And Reach Test } \\
\hline Age & $\mathrm{n}$ & $\begin{array}{c}\text { Means } \\
\text { degrees }\end{array}$ & $\begin{array}{c}\text { Standard } \\
\text { Deviation }\end{array}$ & $\begin{array}{c}\text { Means } \\
\text { centimeter }\end{array}$ & $\begin{array}{c}\text { Standard } \\
\text { Deviation }\end{array}$ \\
\hline 6 & 80 & 24.60 & 8.66 & 27.45 & 5.55 \\
\hline 10 & 104 & 27.39 & 9.30 & 28.29 & 6.39 \\
\hline 14 & 81 & 26.80 & 9.49 & 30.51 & 7.65 \\
\hline
\end{tabular}

Table 2

Means and Standard Deviations by Gender as Measured by the Leighton Flexometer and the SRT

\begin{tabular}{|c|c|c|c|c|c|}
\hline \multicolumn{2}{|c|}{} & \multicolumn{2}{|c|}{ Leighton Flexometer } & \multicolumn{2}{c|}{ Sit And Reach Test } \\
\hline Gender & $\mathrm{n}$ & $\begin{array}{c}\text { Means } \\
\text { degrees }\end{array}$ & $\begin{array}{c}\text { Standard } \\
\text { Deviation }\end{array}$ & $\begin{array}{c}\text { Means } \\
\text { centimeter }\end{array}$ & $\begin{array}{c}\text { Standard } \\
\text { Deviation }\end{array}$ \\
\hline Male & 115 & 24.35 & 7.42 & 26.67 & 6.08 \\
\hline Female & 150 & 27.91 & 10.14 & 30.28 & 6.70 \\
\hline
\end{tabular}


Table 3

Means and Standard Deviations by Ethnic Origin as Measured by the Leighton Flexometer and the SRT

\begin{tabular}{|c|c|c|c|c|c|}
\hline \multicolumn{2}{|c|}{} & \multicolumn{2}{|c|}{ Leighton Flexometer } & \multicolumn{2}{c|}{ Sit And Reach Test } \\
\hline $\begin{array}{c}\text { Ethnic } \\
\text { Origin }\end{array}$ & $\mathrm{n}$ & $\begin{array}{c}\text { Means } \\
\text { degrees }\end{array}$ & $\begin{array}{c}\text { Standard } \\
\text { Deviation }\end{array}$ & $\begin{array}{c}\text { Means } \\
\text { centimeter }\end{array}$ & $\begin{array}{c}\text { Standard } \\
\text { Deviation }\end{array}$ \\
\hline Asian & 90 & 27.07 & 8.90 & 29.47 & 6.47 \\
\hline Bispanic & 91 & 26.55 & 9.49 & 28.59 & 6.81 \\
\hline Caucasian & 84 & 25.42 & 9.28 & 28.04 & 6.73 \\
\hline
\end{tabular}



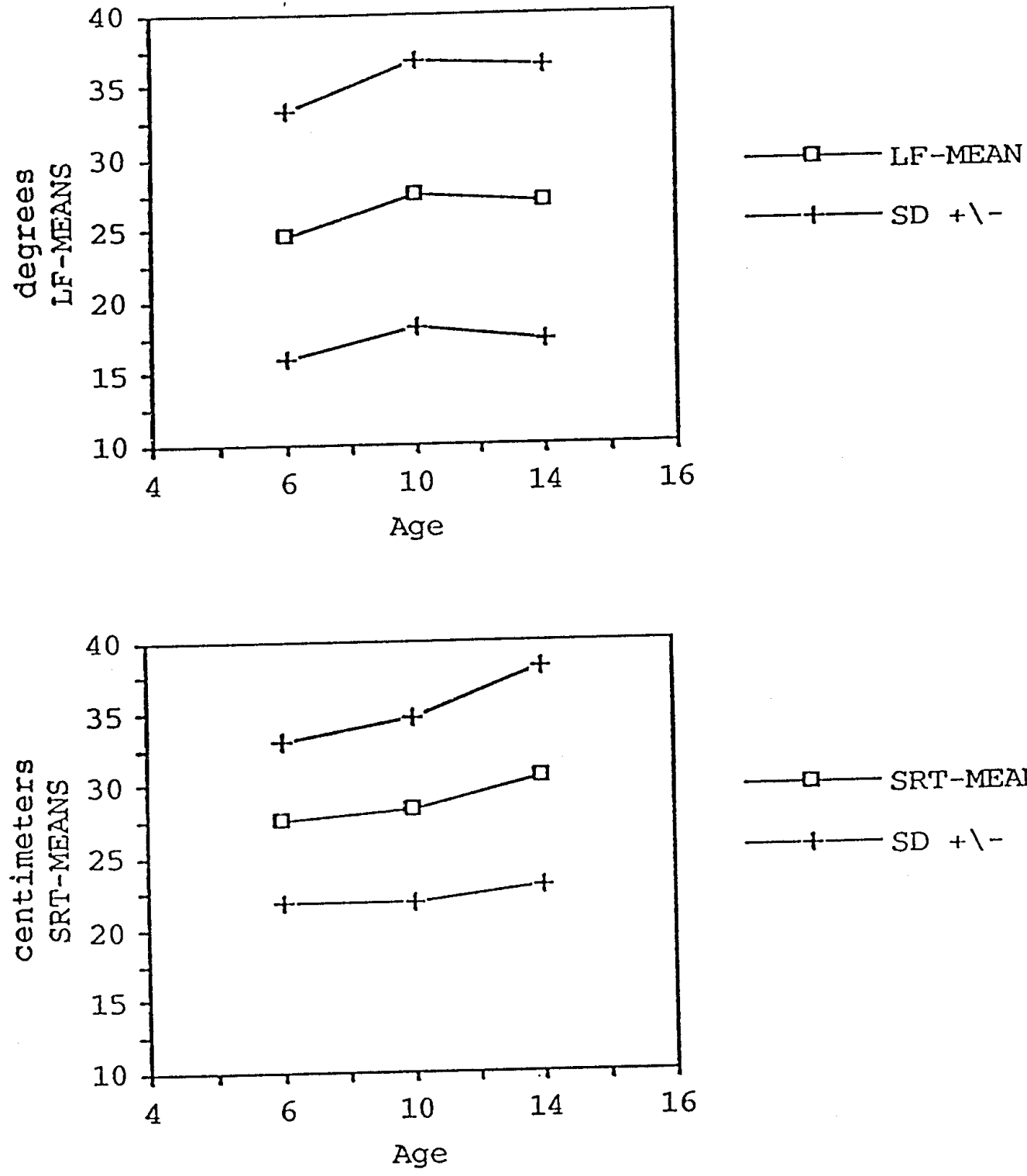

$\longrightarrow$ - SRT-MEAN

$-+-S D+1-$

Eigure 3. Means and Standard Deviations for each Age group for the Leighton Flexometer and the Sit and Reach Test 
To determine if significant differences existed between the mean scores of the age, gender, and ethnic origin groups, a three-way ANOVA was calculated for the Leighton Flexometer and the SRT. The level of significance was set at $p^{<} .05$.

A significant effect for gender $(E(1,265)=10.655$, $\mathrm{p}<.05)$ was found with the Leighton Flexometer Test. No significant effects were found for ethnic origin or age on the Leighton Flexometer test. On the SRT, significant effects were found for gender $(E(1,265)=23.921, \underline{p}<.05)$ and age $(\mathrm{E}(1,265)=5.47, \mathrm{p}<.05)$. No significant effects were noted for ethnic origin on the SRT (Table 4 and 5 ).

In addition, where significant main effects were found, post-hoc Scheffe' tests were conducted. A post-hoc Scheffe' $\mathrm{E}$ test for the Leighton Flexometer showed significant differences in flexibility between males and females, with females showing more flexibility than the males. A post-hoc Scheffe' E test for the SRT showed significant differences between males and females, with the females showing more flexibility than the males. A post-hoc scheffe' $E$ test for the SRT also showed significant differences between the six and fourteen year-olds (Table 6 ).

To determine the relationship of the results found by the SRT and the Leighton Flexometer, a Pearson Product Moment correlation was calculated. Results showed a moderate correlation between the two instruments $(r=.682)$ (Table 7 
and Figure 4). The positive linear correlation between the measures of the two instruments is illustrated in Figure 4 .

Table 4

ANOVA Table for the 3-Factor Analysis of Variance of Leighton Flexometer Data

\begin{tabular}{|c|c|c|c|c|c|}
\hline Source & df: & $\begin{array}{c}\text { Sum of } \\
\text { Squares }\end{array}$ & $\begin{array}{c}\text { Mean } \\
\text { Square }\end{array}$ & F-Test & P Value \\
\hline $\begin{array}{c}\text { Ethnic } \\
\text { Origin }\end{array}$ & 2 & 111.175 & 55.587 & .704 & .4956 \\
\hline Gender & 1 & 841.462 & 841.462 & 10.655 & .0013 \\
\hline Age & 2 & 405.445 & 202.723 & 2.567 & .0788 \\
\hline Interaction & 4 & 106.944 & 26.736 & .339 & .8518 \\
\hline Error & 247 & 19506.2 & 78.973 & & \\
\hline
\end{tabular}

Table 5

ANOVA Table for the 3-Factor Analysis of Variance of SRT Data

\begin{tabular}{|c|c|c|c|c|c|}
\hline Source & df: & $\begin{array}{c}\text { Sum of } \\
\text { Squares }\end{array}$ & $\begin{array}{c}\text { Mean } \\
\text { Square }\end{array}$ & F-Test & Palue \\
\hline $\begin{array}{c}\text { Ethnic } \\
\text { Origin }\end{array}$ & 2 & 113.661 & 56.831 & 1.491 & .2271 \\
\hline Gender & 1 & 911.568 & 911.568 & 23.921 & .0001 \\
\hline Age & 2 & 416.941 & 208.471 & 5.471 & .0047 \\
\hline Interaction & 4 & 207.739 & 51.935 & 1.363 & .2474 \\
\hline Error & 247 & 9412.641 & 38.108 & & \\
\hline
\end{tabular}


Table 6

Post-Hoc Scheffe' Analysis of Significant Main Effects for Age as Measured by the SRT

$\begin{array}{lcc}\text { Age } & \text { Mean Difference: } & \text { Scheffe' F Test } \\ 6 \text { vs. } 10 & -.838 & .367 \\ 6 \text { vs. } 14 & -3.056 & 4.341 * \\ 10 \text { vs. } 14 & -2.218 & 2.586 \\ *(\mathrm{p}<.05) & & \end{array}$

Table 7

Pearson Product Moment Correlation Coefficient

Between the Leighton Flexometer and the SRT Measures

\begin{tabular}{|c|c|c|c|}
\hline Count & Covariance & Correlation & R-squared \\
\hline 265 & 41.939 & $.682 *$ & .465 \\
\hline
\end{tabular}

* $(\mathrm{p}<.05)$ 


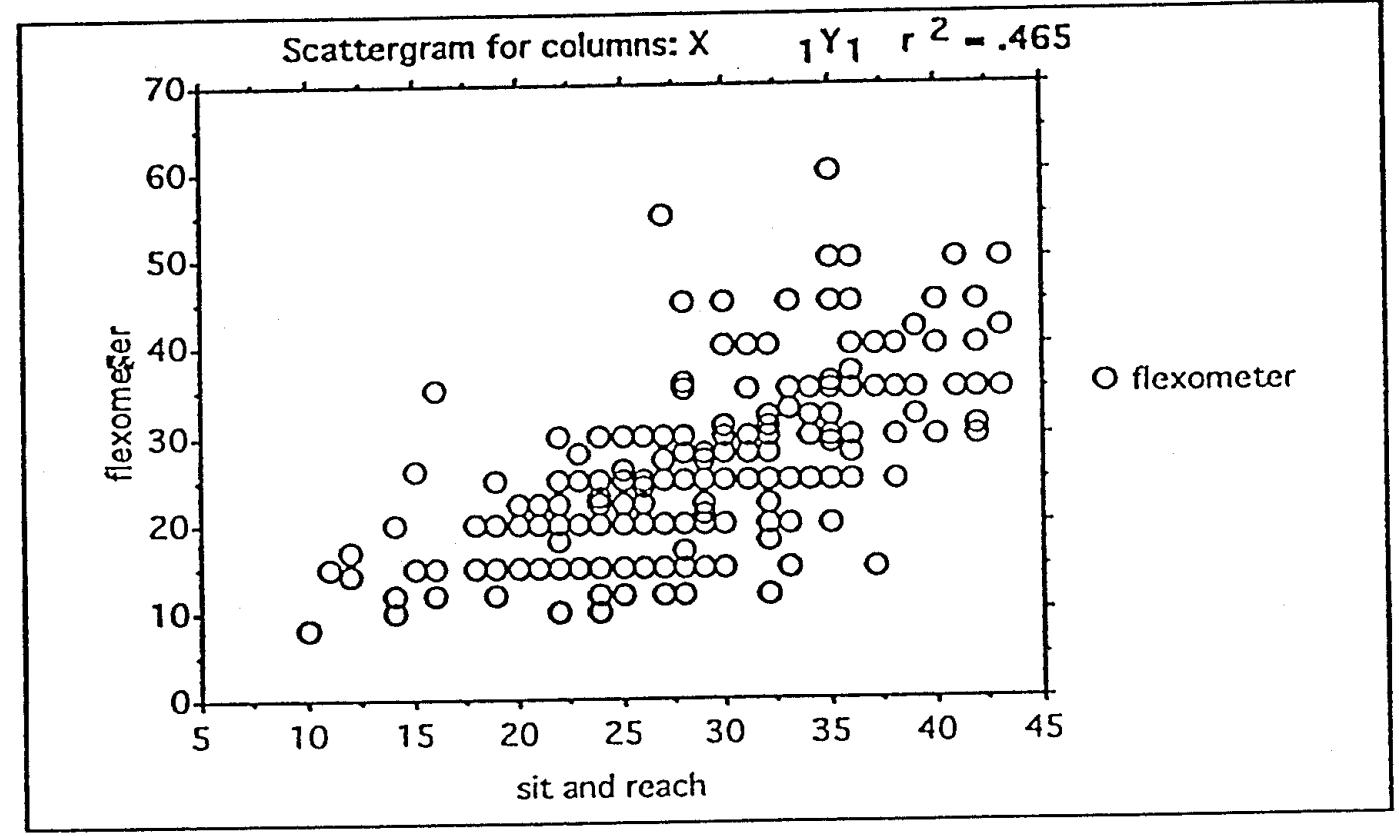

Eigure 4. Scattergram of Flexibility as Measured by the Sit and Reach Test and the Leighton Flexometer. 


\section{Discussion}

Four hypotheses were tested in this study. Each hypothesis will be addressed separately, followed by a discussion, based on the results.

Hypothesis one stated that a significant age effect would be found with younger subjects showing greater flexibility. Based on the statistical analysis, the hypothesis was rejected. The Scheffe' post-hoc analysis for the SRT showed significant differences between the age groups of six and fourteen year-olds with the fourteen year-olds having the most flexibility. The higher scores of flexibility by the fourteen year-olds versus the lower scores obtained by the six year-olds have also been indicated by Ross and Gilbert (1985) who presented the average scores for gender by age on the SRT. These differences are in direct contrast with the study by Shephard (1986), which reflected the general loss of flexibility with aging subjects 45-75 years of age. The decline in flexibility found in older subjects is also in agreement with other studies (Buxton, 1957; Gallahue, 1982; Harris, 1969; Hupprich \& Sigerseth, 1950; Kendall \& Kendall, 1971; and Ross \& Gilbert, 1985). In Shephard's (1986) study, cross-sectional analyses of the SRT scores showed a trend of decreased flexibility with aging when an age-gender interaction term was introduced. This may suggest that flexibility loss occurs more in adults than 
children. The differences in scores found in the present study may be due to the six year-olds' lack of motivation and knowledge in performing the flexibility skill, but is most likely attributed to growth, social expectations, and puberty (Thomas \& French, 1985).

Hypothesis two stated that a significant gender effect would be found with female subjects showing greater flexibility. The hypothesis was accepted. Like the findings of the present study, Docherty and Bell (1985), Thomas, Nelson, \& Church (1988), and Shephard, Berridge \& Montelpare (1990) measured lower back flexion and hip flexion and found that the females scored significantly better than the males. Thomas, Nelson, and Church (1988) also supported these findings. In their study of gender differences on the SRT, females were more flexible than the males at all ages (Thomas, Nelson, \& Church, 1988). Since rapid growth is an outstanding feature of adolescence, change in body size may influence flexibility. It is also possible that alterations in habitual movement patterns are partially responsible for changes in range of motion (Clark, 1975). Thus, the results obtained from these studies confirm and strengthen the conclusion regarding the effects of gender on flexibility. The third hypothesis addressed in this study stated that no significant difference would be found in flexibility between ethnic origins. The hypothesis was accepted. This 
study showed that there were no differences between Caucasians and Asians, Asians and Hispanics, and Caucasians and Hispanics. This might be explained by the social equality of all three ethnic groups.

Finally, the fourth hypothesis stated that a strong correlation would be observed for flexibility as measured by the SRT and the Leighton Flexometer. Results indicated that the SRT and the Leighton Flexometer had a moderate correlation. Even though the SRT score provided a simple measure of flexibility in the lumbar spine, and hamstring muscles, controversy exists over whether the SRT takes in other anthropometric factors like arm, leg, and trunk length, and pelvic involvement. For an example, Jackson and Baker (1986) conducted a study that examined the relationships between the SRT and criterion measures of hamstring and low back flexibility. Results indicated that the SRT appears to possess moderate validity as a hamstring flexibility measure, but a low correlation $(x=.28$ ) with low back flexibility. They concluded that the SRT was not a valid test for flexibility. The present study did not isolate these anthropometric factors and measured only overall flexibility. This should be noted when interpreting the present results. 
Chapter 5

SUMMARY, CONCLUSIONS, AND RECOMMENDATIONS

Summary

The major purpose of this study was to examine the effects of age, gender, and ethnic origin on flexibility as measured by the SRT and the Leighton Flexometer. Two hundred and sixty five volunteers served as subjects in this study; they were divided into three age groups $(6,10$, and 14), and three ethnic origins (Asians, Caucasians, and Hispanics). The SRT and the Leighton Flexometer were used to collect the data.

Results revealed significant differences among age groups for flexibility, particularly between the six and fourteen year-olds for the SRT. No significant differences were noted for the Leighton Flexometer for age. Comparison of flexibility by gender revealed that the females scored significantly higher than the males on both instruments. Comparison of ethnic origin revealed no significant differences for either the SRT or the Leighton Flexometer. Finally, inspection of the results showed only a moderate correlation between the SRT and the Leighton Flexometer for the determination of flexibility. The SRT and the Leighton Flexometer measured overall flexibility and may not take into account other anthropometric factors that may be factors. 


\section{conclusions}

Based on the results of this study the following conclusions may be drawn:

1. The age level comparisons provided results that are consistent with previous research which has reported increasing motor performance differences between subjects as age increases, with the exception of the difference noted between the ten and fourteen year-olds as measured by the Leighton Flexometer.

2. The data presented were consistent with the current research that females are more flexible than males, in the age ranges tested, as measured by the SRT and the Leighton Flexometer.

3. No significant differences were noted between ethnic origins.

4. The SRT and the Leighton Flexometer were found to be efficient measuring devices for the measurement of flexibility. Results showed that the method of administration was convenient for the tester and the subjects and the testing time frame was minimal. However, due to the controversy of the possible involvement of the pelvic tilt, arm, leg, and trunk length, and of hip movement, the instruments may not be appropriate for overall lower back testing. 
5. A moderate correlation was found for flexibility between the SRT and the Leighton Flexometer $(r=.68)$. The researcher questions why there wasn't a higher correlation between the two measuring instruments. Additional research is needed to answer this question.

\section{Recommendations}

Based on the conclusions mentioned, the following recommendations are made:

1. Evaluation of flexibility should start at an early age and be consistent in testing throughout the growing years of the adolescent. This evaluation is needed because there are significant changes in flexibility as the subject matures. Future research needs to examine what factors contribute to age differences in flexibility.

2. All gender differences may be influenced by the expectations society has for females and males. After puberty, males have a larger muscle mass and a longer period of growth while females add essential fat at puberty (Thomas \& French, 1985). Females and males should participate and perform at a similar level in all activities. This would ensure that differences in motor performance are minimized and not due to any outside factors other than growth. Since the socioeconomic backgrounds of the subjects in this research were not studied, explaining the 
relationship of these variables to flexibility was not possible.

3. Future research needs to examine appropriate measurements of flexibility for health-related purposes. Should flexibility be assessed in terms of anterior flexion? Development of a field test to assess flexibility may be an appropriate research goal.

4. Investigations comparing the motor performance of populations from various ethnic origins have yielded conflicting results (DiNucci \& Shows, 1977; Kaufman, 1973; Ponthieux \& Barker, 1965; Stone, 1966). More research is needed to examine the possibility of statistically significant ethnic differences in flexibility to determine if cultural and social expectations played a factor.

5. Future research should take into consideration the additional factors of the involvement of pelvic tilt, hip flexion, trunk, leg, and arm length when examining the results of the SRT.

6. Future research is needed to examine the incidence of the moderate correlation found between the SRT and the Leighton Flexometer. Additional testing may indicate different results or a higher correlation. 
References

American Alliance for Health, Physical Education, Recreation, and Dance (1980). Lifetime health-related fitness test manual. Reston, VA: AAHPERD.

AAHPERD (1984). Technical manual for the health related physical fitness test. Washington, DC: Author. AAHPERD (1988). Physical Best. Washington, DC: Author. American Academy of Orthopaedic Surgeons (1966) - Jeint motion: Methed of measuring and recerding Edinburgh: Livingstone.

Bischoff, J., \& Lewis, K. (1987). A cross-sectional study of fitness levels in a movement education program. Research Quarterly for Exercise and Sport, 58(3), 348-353. Broer, M., \& Galles, N. (1958). Importance of relationship between various body measurements and performance of toe-touch test. Research Quarterly for Exercise and Sport, $29,253-263$.

Burdett, R.G., Brown, K.E., \& Fall, M.P. (1986). Reliability and validity of four instruments for measuring lumbar spine and pelvic positions. Physical Therapy, 66, $677-684$ Buxton, D. (1957). Extension of the Kraus-Weber Test. Research Quarterly, 28, 210-217. 
Clark, H.H. (1975). Joint and body range of movement. Physical Fitness Research Digest, 5(4), 1-22. Cornbleet, S.L., \& Woolsey, N.B. (1991). Critical analysis of the sit and reach test. Physical Therapy, 6(71), supplement.

Cuerton, T.K. (1941). Flexibility as an aspect of physical fitness. Supplement to Research Quarterly, 12, 381-390. DiNucci, J., \& Shows, D. (1977). A comparison of the motor performance of black and caucasian girls. Research Quarterly, 48, 679-684.

Docherty, D., \& Bell R. (1985). The relationship between flexibility and linearity measures in boys and girls 6-15 years of age. Journal of Human Movement Studies, 11, 279-288.

Eaton, W. O., \& Enns, I.R. (1986). Sex differences in human motor activity level. Esychology Bulletin, 100, 19-28. Ekstrand, J., Wiktorsson, M., Oberg, B., \& Gillquist, J. (1982). Lower extremity goniometric measurements: To study their reliability. Archives Physical Medical Rehabilitation, 63, 171-175.

Farrell, J. (1982). Acomparison of twe conservative treatment approaches to acute low back pain. Unpublished master's thesis, Western Australian Institute of Technology, Sidney, Australia. 
Finneson, B. (1973). Low back pain. Philadelphia: J.B. Lippincott Co.

Fitness and Lifestyle Research Institute (1983). Fitness and lifestyle in Canada. Ottawa: Author.

Fox, E., Kirby, T., \& Fox, A. (1987). Bases of fitness. New York: MacMillan Publishing Company.

Frost, M. Stuckey, S., \& Smalley, L. (1982). Reliability of measuring trunk motions in centimeters. Physical Therapy, 62, 1431-1437.

Gallahue, D.L. (1982). Understanding motor development in children. New York: John Wiley \& Sons.

Harris, M. (1969). Flexibility. Physical Therapy, $-(6)$, 591-600.

Hart, D.L., \& Rose, S. (1986). Reliability of a non-invasive method for measuring the lumbar curve. Journal of orthopaedic and Sports Physical Therapy, 8, 180-184. Hart, F.D., Strickland D., \& Cliffe, P. (1979). Measurement of spinal mobility. Annals of Rheumatic_Diseases, 33 , 136-139.

Headley, B. (1990). EMG and low back pain. Clinical Management, $10(3), 13-22$. Hedges, L, V., \& Olkin, I. (1985). Statistical methods for meta-anaylsis. New York: Academic Press. Hoppenfeld, S. (1976). Physical examination of the spine and extremities. Connecticut: Appleton Century-Crofts. 
Hupprich, F., \& Sigerseth, P. (1950). The specificity of flexibility in girls. Research Quarterly, 21, 25-33.

Hutinger, P. (1959). Differences in speech between American negro and white children in performance of the 35-yard dash. Research Quarterly, 30, 366-368.

Hyde, J. S. (1984). How large are gender differences in aggression? A developmental meta-analysis. Development Psychelogy, 20, 722-736.

Jackson, A., \& Baker, A. (1986). The relationship of the sit and reach test to criterion measures of hamstring and back flexibility in young females. Research Quarterly for Exercise and spert, 57(3), 183-186.

Jackson, A., \& Langford, N. (1989). The criterion-related validity of the sit and reach test: Replication and extension of previous findings. Research Quarterly for Exercise and sport, $60(4), 384-387$.

Johnson, R., \& Lavay, B. (1988). Kansas adapted special physical education test manual: Health related fitness and psychomotor testing. Kansas state Department of Education.

Kaufman, A., \& Kaufman, N. (1973). Black-white differences at ages $21 / 2-81 / 2$ on the McCarthy scales of children abilities. Journal of School Psychology, 11, 196-206. Kendall, H., \&endall, P. (1971). Muscles, testing, and function. Baltimore: williams and wilkins Company. 
Kippers, V., \& Parker, A. (1987). Toe-touch test: A measure of its validity. Physical Therapy, 67(11), 1680-1684. Kraus, H., \& Hirschland, A.R. (1954). Minimum muscular fitness tests in school children. Research Quarterly, 25, $178-188$.

Kraus, H., Weber, S., (1945). Evaluation of posture based on structural and functional movements. Physical Therapy Review, 25, 267-271.

Lee, A., (1980). Child-rearing practices and motor performance of black and white children. Research Quarterly For Exercise and Sport, 51(3), 494-500.

Leighton, J. (1942). A simple objective and reliable measure of flexibility. Research Quarterly, 205-216.

Leighton, J. (1955). An instrument and technique for the measurement of range of joint motion. Archives of Physical Medicine and Rehabilitation, pp. 571-574.

Loebl, W.Y. (1967). Measurement of spinal posture and range of spinal movement. Annals of Physical Medicine, 2, 103-110.

Lovell, F., Rothstein, J., \& Personius, W. (1989). Reliability of clinical measurements of lumbar lordosis taken with a flexible ruler. Physical Therapy, 62(2), 96-105.

Maccoby, E., \& Jacklin, C. (1974). The psychology of sex differences. Stanford, CA: Stanford University Press. 
Macrae, I. \& Wright, V. (1969). Measurement of back movement, Annals of Rheumatic Disease, 28, 584-589.

Malina, R.M. (1968). Growth, maturation, and performance of Philadelphia negre and white elementary school children. Unpublished doctoral dissertation, University of Pennsylvania.

Merritt, J., McLean, T., Erickson, R., \& Clifford, K. (1986). Measurement of trunk flexibility in normal subjects: Reproducibility of three clinical methods. Maye clinical Procedure, 61, 192-197. Morris, A., Williams, J., Atwater, A., \& Wilmore, J. (1982). Age and sex differences in motor performance of 3 to 6 year old children. Research Quarterly for Exercise and Sport, 53(3), 214-221.

Nelson, J., Thomas, J., \& Nelson, K. (1986). Gender differences in children's throwing performance: Biology and environment. Research Quarterly for Exercise and Sport, 57(4), 280-287.

Orthner,B.F. (1969). Parental religiesity and attitudes concerning children. Unpublished master's thesis, Florida State University.

Ponthieux, N. A., \& Barker, D. G. (1965). Relationships between race and physical fitness. Research Quarterly, $36,468-472$ 
Reynolds, P. (1975). Measurement of spinal mobility: A comparison of three methods. Rheumatolegy Rehabilitation, $14,180-185$.

Ross, J., \& Gilbert, G. (1985). The national children and youth fitness study: A summary of findings. Journal of Physical Education, Recreation, and Dance, 56(1), 45-50. Ross, J. G., Pate, R. R., Lohman, T. G., \& Christensen, G. M. (1987). Changes in body composition of children. Journal of Physical Education, Recreation, and Dance, 58(9), 74-77.

Scott, R., Ferguson, A., Jenkins, M., \& Cutter, F. (1955). Growth and development of negro infants. Pediatrics, 16, 21-29.

Scott, M., French, G., \& French, E. (1959). Measurement and exaluation in physical education. Dubuque, Iowa: William C. Brown Co.

Shephard, R., Berridge, M., \& Montelpare, W. (1990). On the generality of the sit and reach test: an analysis of flexibility data for an aging population. Research Quarterly for Exercise and Sport, 61(4), 326-330. Sigerseth, P. (1978). Elexibility: An introduction to measurement in physical education. Boston: Allyn and Bacon . 
Stone, W. J. (1966). The influence of race and socioeconomic status on physical performance. Dissertationabstracts International, 2703A-661.

Thomas, J., Nelson, J., \& Church, G. (1988). A developmental analysis of gender differences on health-related physical fitness. Unpublished manuscript, Arizona State University.

Thomas. J., \& French, K. (1985). Gender differences across age in motor performance: A meta-analysis. Psychelegical Bulletin, 98, 260-282.

Troup, J.D.G., Hood, C.A., \& Chapman, A.E. (1976). Measurement of the saggittal mobility of the lumbar spine and hips. Unpublished manuscript, Biomechanics Laboratory, Department of Anatomy, Royal Free Hospital School of Medicine, London. Troup, J.D.G. (1979). Biomechanics of the vertebral column. Physiotherapy, 65, 238-244.

Twomey, L. (1987). Physical Therapy of the Jow Back. New York: Churchill Livingstone, N.L. Wells, K., \& Dillion, E. (1952). The sit and reach: A test of back and leg flexibility. Research Quarterly for Exercise and Sport, 23, 115-118. 
APPENDIX A 


\section{Dear Parents:}

This is to inform you that some children in the classes of the Sunnyvale School District will be participating in a Physical Education (P.E.) study conducted by Susan De La Torre. The children will be administered the Sit and Reach Test and be measured for low back flexibility using the Leighton Flexometer. They will be tested on May 11-15, 1992 during their regular P.E. period. The results of this study should increase our understanding and knowledge of flexibility in children and of the instruments currently being used. Benefits of this study, for the children, could include a chance to participate in a research experiment, have fun, and learn more about their physical capabilities involving flexibility.

You should understand that your child's participation is voluntary and that choosing not to participate in this study, or any part of this study, will not affect his/her relations with the teacher or school district.

As with any form of exercise and stretching, injury may occur. The Sit and Reach Test is a mandated state physical fitness test, and is believed to be quite safe.

The results of this study may be published, but any information that could result in your child's identification will remain confidential.

To provide a complete and accurate sample, please complete the questions below regarding your child:

1. Birthdate

2. Please circle the appropriate designation for your ethnic orgin.

$\begin{array}{lll}\text { American Indian } & \text { Hawaiian } & \text { Thai } \\ \text { Asian } & \text { Hispanic } & \text { White, Non-Hispanic } \\ \text { Asian Indian } & \text { Japanese } & \text { Other } \\ \text { Black/African American Korean } & \text { Decline-to-state } \\ \text { Cambodian } & \text { Laotian } & \\ \text { Central American } & \text { Other Asian } \\ \text { Chicano/Hispanic } & \text { Pacific Islander } \\ \text { Chinese } & \text { Puerto Rican } \\ \text { Cuban } & \text { Samoan } \\ \text { Filipino } & \text { South American } \\ \text { Guamanian } & \text { Southeast Vietnamese }\end{array}$


3. Previous injury to low back (yes, no)

if yes, please explain briefly the injury.

If you have questions about this study, I will be happy to talk with you. I can be reached at (408) 866-4878. If you have questions or complaints about research subject's rights, or in the event of a research related injury, please contact Dr Greg Payne, Thesis Advisor, at (408) 924-3028 or Serena Stanford, Ph.D. Associate Academic Vice President for Graduate Studies and Research, at (408) 924-2480.

* The signature of a subject on this document indicates your approval for your child to participate in the study.

* The signature of a researcher on this document indicates agreement to include the above named subject in the research and that the subject has been fully informed of his or her rights.

* The signature of the parent/guardian on this document indicates agreement for his/her child to participate in the study.

Parent/guardian's Signature

Date

Child's signature Date

Researcher's Signature Date 
APPENDIX B 


\title{
EVERGREEN SCHOOL DISTRICT H
}

February 19, 1992

\author{
Susan De La Torre \\ SuSU \\ School of Applied Arts and Sciences \\ Department of Human Performance \\ One Washington Square \\ San Jose, CA 95192-0054 \\ Dear Susan,
}

The Evergeen School District is granting you permission to conduct your study of student flexibility using the Sit and Reach Test and the Leighton Flexometer. It is our understanding prior permission will be obtained from the students, parents, teachers, and principals involved. Student identification will remain confidential.

Good luck on your study and Mater's Thesis. We look forward to learning more about student flexibility from your study.

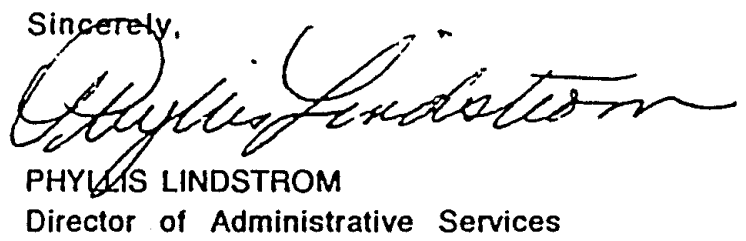

bh

District Administration Office

3188 Quimby Road

San Jose, California 95148

Telephone: (408) 270-6800
Superintendent: James F. Smith Governing Board: Carolyn Clark Kathy Atwood Tom Matsumoto Kathy Bowers Jeff Fischer 
APPENDIX C 
May 5, 1992

To Whom It May Concern:

Susan De La Torre has permission to complete her research for her Master's Thesis at Sunnyvale Middle School. This will be conducted the week of May 11, 1992.

Sincerely,

Masey Lander

Nancy Lander

Principal

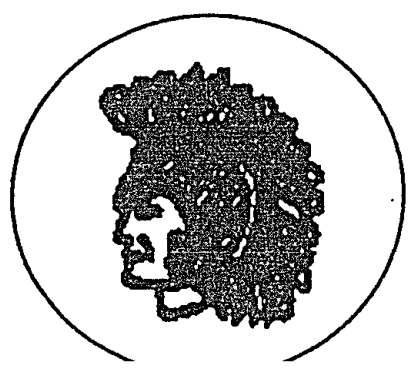


APPENDIX D 
Susan De La Torre

1127 Denver Dr.

Campbell, Ca. 95008

Dear Ms. De La Torre:

Thank you for your recent request to use material from one or more of our publications in your thesis.

The quoted materlal may be included in your manuscript, using the standard format and footnotes suggested in the UNIVERSITY OF CHICAGO STYLE MANUAL or those required by your university.

However, If your thesis is selected for publication and a contractual agreement has been slgned, then you should submtt your formal permission request to this office. Please advise the name of your publisher, tentative publication date, number of pages in your forthcoming book and the estimated reta1l price. Upon receipt of this Information this office shall then research your request and respond with the conditions of the permission.

This course of action must be taken since many times representation of the copyrighted material may change between the time a thesis is submitced and the date that a contractual arrangement for publication has been secured.

Congratulations as you complete your advanced studies, and with very best wishes for your future work!

Sincerely,

Mierie, t' il'oigne.

Marle P. Wayne

Permissions Assistant

J. B. LIppincott Company 